\title{
Analysis of Halogen-Mercury Reactions in Flue Gas
}

Final Technical Report

Reporting Period Start Date: 01/02/2006 (DOE)

Report Period End Date: 12/31/2009 (DOE)

Principal Authors: Paula A. Buitrago ${ }^{1}$, Geoffrey D. Silcox ${ }^{1}$,Constance L. Senior ${ }^{2}$, Brydger Van Otten ${ }^{2}$

Issue date: April 2010

DOE Award Number: DE-FG26-06NT42713

Project Officer: Andrew O’Palko

EPRI U of U Agreement Number: EP-P29435C13889

Project Period: 12/01/2009 - 03/01/2010

Project Officer: Ramsay Chang

${ }^{1}$ University of Utah

Department of Chemical Engineering

50 S. Central Campus Drive, MEB 3290

Salt Lake City, Utah

${ }^{2}$ Reaction Engineering International

77 West 200 South, Suite 210

Salt Lake City, UT 84101 


\section{DISCLAIMER AND LEGAL NOTICE}

This work was supported in part through the DOE NETL University Coal Research Program (UCR) grant to the University of Utah (DOE Award Number DE-FG2606NT42713). This report was prepared as an account of work sponsored by an agency of the United States Government. Neither the United States Government nor any agency thereof, nor any of their employees, makes any warranty, express or implied, or assumes any legal liability or responsibility for the accuracy, completeness, or usefulness of any information, apparatus, product, or process disclosed, or represents that its use would not infringe privately owned rights. Reference herein to any specific commercial product, process, or service by trade name, trademark, manufacturer, or otherwise does not necessarily constitute or imply its endorsement, recommendation, or favoring by the United States Government or any agency thereof. The views and opinions of authors expressed herein do not necessarily state or reflect those of the United States Government or any agency thereof.

This report was prepared by the University of Utah and Reaction Engineering International as an account of work sponsored in part by the Electric Power Research Institute, Inc. (EPRI). Neither EPRI, members of EPRI, the University of Utah, Reaction Engineering International, nor any person acting on their behalf: (i) makes any warranty, express or implied, with respect to the use of any information, apparatus, method, or process disclosed in this report or that such use may not infringe privately owned rights: or (ii) assumes any liabilities with respect to the use of, or for damages resulting from the use of, any information, apparatus, method, or process disclosed in this report. 


\begin{abstract}
Oxidized mercury species may be formed in combustion systems through gas-phase reactions between elemental mercury and halogens, such as chorine or bromine. This study examines how bromine species affect mercury oxidation in the gas phase and examines the effects of mixtures of bromine and chlorine on extents of oxidation. Experiments were conducted in a bench-scale, laminar flow, methane-fired (300 W), quartz-lined reactor in which gas composition $\left(\mathrm{HCl}, \mathrm{HBr}, \mathrm{NO}_{\mathrm{x}}, \mathrm{SO}_{2}\right)$ and temperature profile were varied. In the experiments, the post-combustion gases were quenched from flame temperatures to about $350^{\circ} \mathrm{C}$, and then speciated mercury was measured using a wet conditioning system and continuous emissions monitor (CEM). Supporting kinetic calculations were performed and compared with measured levels of oxidation.
\end{abstract}

A significant portion of this report is devoted to sample conditioning as part of the mercury analysis system. In combustion systems with significant amounts of $\mathrm{Br}_{2}$ in the flue gas, the impinger solutions used to speciate mercury may be biased and care must be taken in interpreting mercury oxidation results. The stannous chloride solution used in the CEM conditioning system to convert all mercury to total mercury did not provide complete conversion of oxidized mercury to elemental, when bromine was added to the combustion system, resulting in a low bias for the total mercury measurement. The use of a hydroxylamine hydrochloride and sodium hydroxide solution instead of stannous chloride showed a significant improvement in the measurement of total mercury.

Bromine was shown to be much more effective in the post-flame, homogeneous oxidation of mercury than chlorine, on an equivalent molar basis. Addition of NO to the flame (up to $400 \mathrm{ppmv}$ ) had no impact on mercury oxidation by chlorine or bromine. Addition of $\mathrm{SO}_{2}$ had no effect on mercury oxidation by chlorine at $\mathrm{SO}_{2}$ concentrations below about 400 ppmv; some increase in mercury oxidation was observed at $\mathrm{SO}_{2}$ concentrations of 400 ppmv and higher. In contrast, $\mathrm{SO}_{2}$ concentrations as low as 50 ppmv significantly reduced mercury oxidation by bromine, this reduction could be due to both gas and liquid phase interactions between $\mathrm{SO}_{2}$ and oxidized mercury species. The simultaneous presence of chlorine and bromine in the flue gas resulted in a slight increase in mercury oxidation above that obtained with bromine alone, the extent of the observed increase is proportional to the chlorine concentration. The results of this study can be used to understand the relative importance of gas-phase mercury oxidation by bromine and chlorine in combustion systems.

Two temperature profiles were tested: a low quench $(210 \mathrm{~K} / \mathrm{s})$ and a high quench (440 $\mathrm{K} / \mathrm{s}$ ). For chlorine the effects of quench rate were slight and hard to characterize with confidence. Oxidation with bromine proved sensitive to quench rate with significantly more oxidation at the lower rate.

The data generated in this program are the first homogeneous laboratory-scale data on bromine-induced oxidation of mercury in a combustion system. Five $\mathrm{Hg}-\mathrm{Cl}$ and three $\mathrm{Hg}-$ $\mathrm{Br}$ mechanisms, some published and others under development, were evaluated and 
compared to the new data. The Hg-halogen mechanisms were combined with submechanisms from Reaction Engineering International for $\mathrm{NO}_{\mathrm{x}}, \mathrm{SO}_{\mathrm{x}}$, and hydrocarbons. The homogeneous kinetics under-predicted the levels of mercury oxidation observed in full-scale systems. This shortcoming can be corrected by including heterogeneous kinetics in the model calculations. 


\section{TABLE OF CONTENTS}

DISCLAIMER AND LEGAL NOTICE...................................................................... ii

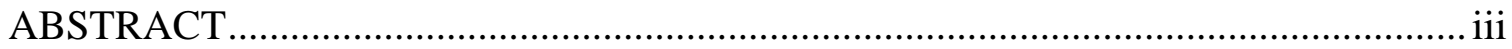

EXECUTIVE SUMMARY …………………………........................................ vi

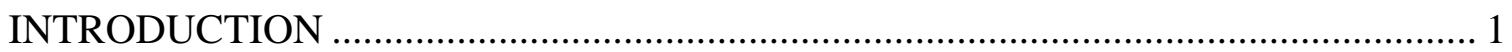

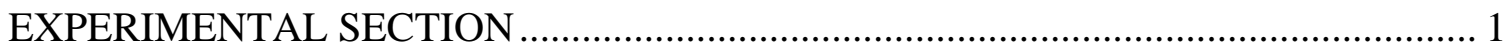

RESULTS AND DISCUSSION ……………………………………………………. 5

Effect of Impinger Chemistry ………………………........................................... 5

Effects of Mixtures of Bromine and Chlorine on Homogeneous Oxidation ................ 13

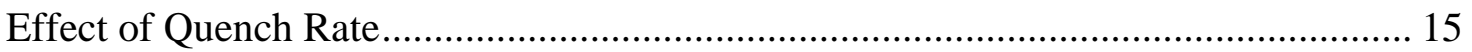

Effect of Acid Gas Species ……………………….............................................. 17

Modeling Gas-Phase Kinetics of Mercury Oxidation by Halogens.............................. 22

Mercury Oxidation by Chlorine.................................................................................. 27

Mercury Oxidation by Bromine............................................................................... 32

Implications for Full-Scale Systems ....................................................................... 35

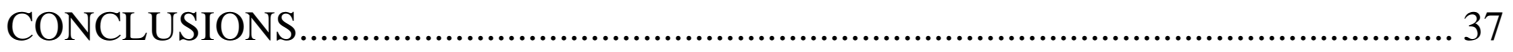

GRAPHICAL MATERIAL LIST............................................................................ 39

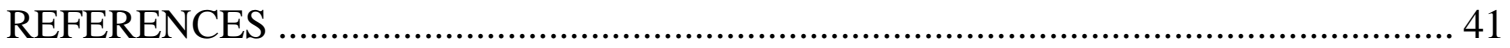

LIST OF ACRONYMS AND ABBREVIATIONS …………………………………... 45 


\section{EXECUTIVE SUMMARY}

Laboratory studies show that increasing the chlorine content of combustion exhaust gases results in an increase in the amount of mercury in the exhaust gas in an oxidized form. ${ }^{1,2,3,4}$ Utility boiler field-test data show that the chlorine content of the coal has some impact on the speciation of mercury at the inlet to the air pollution control device(s) ${ }^{5,6}$ Comparatively little has been published about the effects of bromine on mercury speciation. ${ }^{7,8}$ The impacts of bromine and chlorine on mercury speciation in combustion systems are significantly different. We observed 5 percent mercury oxidation with 400 ppmv chlorine (as $\mathrm{HCl}$ equivalent) and more than 80 percent with $50 \mathrm{ppmv}$ bromine (as $\mathrm{HBr}$ equivalent). When both bromine and chlorine are present, a slight increase in mercury oxidation is observed. The extent of oxidation by bromine was dependent on the temperature profile and appeared to be sensitive to $\mathrm{SO}_{2}$. Sulfur dioxide appears to decrease the level of oxidation by bromine when $\mathrm{SO}_{2}$ is present at concentrations below about 200 ppm, but it is not known whether this effect is due to gas-phase reactions or aqueous-phase impinger chemistry in the sample conditioning system.

A major portion of this project was devoted to improving the sampling conditioning system so that it would function in the presence of bromine. The usual configuration for the total-mercury side of the conditioning system was an impinger containing $5 \mathrm{wt} \%$ $\mathrm{SnCl}_{2}$ and $3 \mathrm{wt} \% \mathrm{HCl}$ in water, followed by an impinger containing $\mathrm{NaOH}$. This configuration resulted in consistently low total mercury readings and was replaced with an impinger containing $4 \mathrm{wt} \%$ of $\mathrm{NH}_{2} \mathrm{OH} * \mathrm{HCl}$ and $20 \mathrm{wt} \% \mathrm{NaOH}$, followed by a $5 \mathrm{wt} \%$ $\mathrm{NaOH}$ solution. The measurements obtained with this new configuration were reproducible for periods of up to two hours and showed a total mercury level that was about $15 \%$ low.

Similarly, the traditional configuration for the elemental-mercury side of the conditioning system was $10 \mathrm{wt} \% \mathrm{KCl}$ in water, followed by an impinger containing $\mathrm{NaOH}$. We observed a bias on the elemental side of the measurement system when chlorine was added as an oxidant and no $\mathrm{SO}_{2}$ was present. This bias was overcome by adding $0.5 \mathrm{wt} \%$ sodium thiosulfate to the $\mathrm{KCl}$-water solution. In order to test for a similar bias when bromine was used as the oxidant, experiments were performed in which the compositions of the solutions on the elemental side of the conditioning system were varied. These tests supported the use of $10 \mathrm{wt} \% \mathrm{KCl}$ and $0.5 \mathrm{wt} \%$ sodium thiosulfate in water, followed by an impinger containing $\mathrm{NaOH}$, when bromine is present.

The presence of $\mathrm{SO}_{2}$ resulted in an apparent reduction in mercury oxidation by bromine, even at concentrations as low as $50 \mathrm{ppm} \mathrm{\textrm {SO } _ { 2 }}$. $\mathrm{SO}_{2}$ concentration measurements made along the reactor and conditioning system as well as the results of injecting $\mathrm{SO}_{2}$ at different points along the system, indicated that the observed inhibitory effect of $\mathrm{SO}_{2}$ was due to interactions between $\mathrm{SO}_{2}$ and oxidized mercury species in the $\mathrm{KCl}$ solution on the elemental side of the conditioning system. The effect of $\mathrm{SO}_{2}$ was reduced by adding an additional $\mathrm{NaOH}$ impinger before the $\mathrm{KCl}$ impinger. 
The data collected in this study show that bromine is a more powerful oxidant than chlorine on an equivalent molar basis. Chlorine concentrations as high as $500 \mathrm{ppm}$ gave less that 10 percent oxidation while bromine concentrations as low as 20 ppm resulted in 80 percent. The extent of mercury oxidation by mixtures of bromine and chlorine was dominated by the bromine with only slight increases upon addition of chlorine.

Two quench rates were examined: 210 and $440 \mathrm{~K} / \mathrm{s}$. The effect of quench rate in the postflame region of the reactor was slight and highly uncertain for chlorine. For bromine, the lower quench rate produced significantly more oxidation.

The effects of $\mathrm{NO}_{\mathrm{x}}$ on oxidation by chlorine and bromine were negligible. The effect of $\mathrm{SO}_{2}$ had little impact on oxidation by chlorine except when the chlorine concentration was greater than $400 \mathrm{ppm}$ (as $\mathrm{HCl}$ equivalent). Understanding the effects of $\mathrm{SO}_{2}$ on oxidation by bromine was complicated by impinger chemistry as noted above.

The data generated in this program are the first homogeneous laboratory-scale data on bromine-induced oxidation of mercury in a combustion system. Five $\mathrm{Hg}-\mathrm{Cl}$ and three $\mathrm{Hg}$ $\mathrm{Br}$ mechanisms were evaluated and compared to the new data. The Hg-halogen mechanisms were combined with sub-mechanisms from Reaction Engineering International for NOx, SOx, and hydrocarbons. The homogeneous kinetics underpredicted the levels of mercury oxidation observed in full-scale systems. This shortcoming can be corrected by including heterogeneous kinetics in the model calculations. 


\section{INTRODUCTION}

At flame temperatures, mercury exists entirely in its elemental form $\left(\mathrm{Hg}^{\circ}\right)$. In the absence of halogens, mercury tends to remain in the elemental form as the combustion gases cool. The elemental form is difficult to remove from exhaust gases. Oxidized forms of mercury, such as $\mathrm{HgCl}_{2}$ and $\mathrm{HgBr}_{2}$, are easily removed from flue gases using existing air pollution control equipment. They are also readily adsorbed by carbon-based sorbents. There is considerable experimental and theoretical evidence that the oxidation of mercury in combustion systems can be achieved by the direct injection of bromine-containing compounds. The data show that bromine is much more effective than chlorine at oxidizing $\mathrm{Hg}^{\circ}$. The objectives of this project are (1) to understand the fundamental gas-phase chemistry of chlorine, bromine, and mercury that leads to the oxidized forms, $\mathrm{HgCl}_{2}, \mathrm{HgBr}_{2}$, and possibly $\mathrm{HgClBr}$, and (2) to be able to predict the extent of oxidation for industrial applications of the technology.

The project investigated halogen-mercury chemistry in experiments conducted in a bench-scale, natural gas-fired, flow reactor. Key parameters that were considered included the temperature profile in the reaction zone, and the concentrations of $\mathrm{NO}_{\mathrm{x}}, \mathrm{SO}_{2}$, and the chemistry of the conditioning system used to prepare gas-phase samples for analysis by atomic fluorescence. The heterogeneous oxidation of mercury on char and activated carbon was not included in this study because of the physical limitations of the reactor.

Various kinetic schemes for homogeneous oxidation were compared to the experimental results. Comparison of the optimum kinetics scheme with full-scale data showed that gas-phase kinetics do not accurately predict mercury behavior in full-scale systems. Heterogeneous kinetics are necessary to accurately model mercury behavior in those systems.

\section{EXPERIMENTAL SECTION}

The homogeneous mercury reactor is shown schematically in Figure 1 along with associated equipment. The reactor consists of a 50-mm OD x 47-mm ID quartz tube (132 $\mathrm{cm}$ in length) located along the center of a high-temperature Thermcraft heater. The tube extends $79 \mathrm{~cm}$ below the heater, is temperature controlled, and has a quartz sampling section attached at the bottom with a capped end. The peak gas temperature in the electrically heated zone was about $1080^{\circ} \mathrm{C}$. The reactor was operated with two temperature or quench profiles: 210 and $440 \mathrm{~K} / \mathrm{s}$. The former will be referred to as low quench (LQ) and the latter as high quench (HQ). The profiles are given in Figure 2 and were obtained by adjusting the current supplied to the heaters surrounding the bottom 79 $\mathrm{cm}$ of the quartz tube.

A 300-W, methane-fired, premixed burner made of quartz glass supplied realistic combustion gasses to the reactor. All reactants were introduced through the burner and passed through the flame to create a radical pool representative of real combustion systems. The burner provided 3.7 SLPM of combustion gases. To study the effects of flue gas components such as $\mathrm{SO}_{2}, \mathrm{NO}, \mathrm{NO}_{2}, \mathrm{HCl}$, and $\mathrm{HBr}$, different concentrations of these or related species were introduced through the burner. 
A Tekran 2537A Mercury Analyzer, coupled with a wet sample conditioning system designed by Southern Research Institute (SRI), provided measurement of total and elemental mercury in the exhaust gas and is shown in Figure 3. Sample gas was pulled in two streams from the last section of the quartz-lined reactor into a set of conditioning impingers. In the standard configuration of the conditioning system, one stream was bubbled through a solution of stannous chloride to reduce the oxidized mercury to elemental form, followed by a solution of sodium hydroxide to remove acid gases. This stream was analyzed to give the total mercury concentration in the sample. The second stream was first treated with a solution of potassium chloride to remove oxidized mercury species, followed by a solution of sodium hydroxide for acid gas removal. This stream was analyzed to give the elemental mercury concentration in the sample. Oxidized species were calculated by the difference between total and elemental mercury concentrations. A chiller removed water from the sample gas and each stream was intermittently sent to the analyzer.

The experiments were performed with different dopants added through the burner. Before adding these, the baseline mercury level at the furnace outlet was checked using a material balance. Experiments were generally repeated at least three times. The error bars shown in the figures below are sample standard deviations.

Table 1 gives the flue gas composition for the experiments. The gas composition was not intended to duplicate the flue gas in coal-fired power plants; the intent of this work was to study reactions of mercury and common flue gas species in a well-controlled system. All species that were added to the reactor $\left(\mathrm{SO}_{2}, \mathrm{NO}, \mathrm{Cl}_{2}, \mathrm{Hg}^{0}\right.$, and $\left.\mathrm{Br}_{2}\right)$ passed through the flame. Their subsequent speciation depended on flame chemistry as well as on the temperature profile in the reactor. 


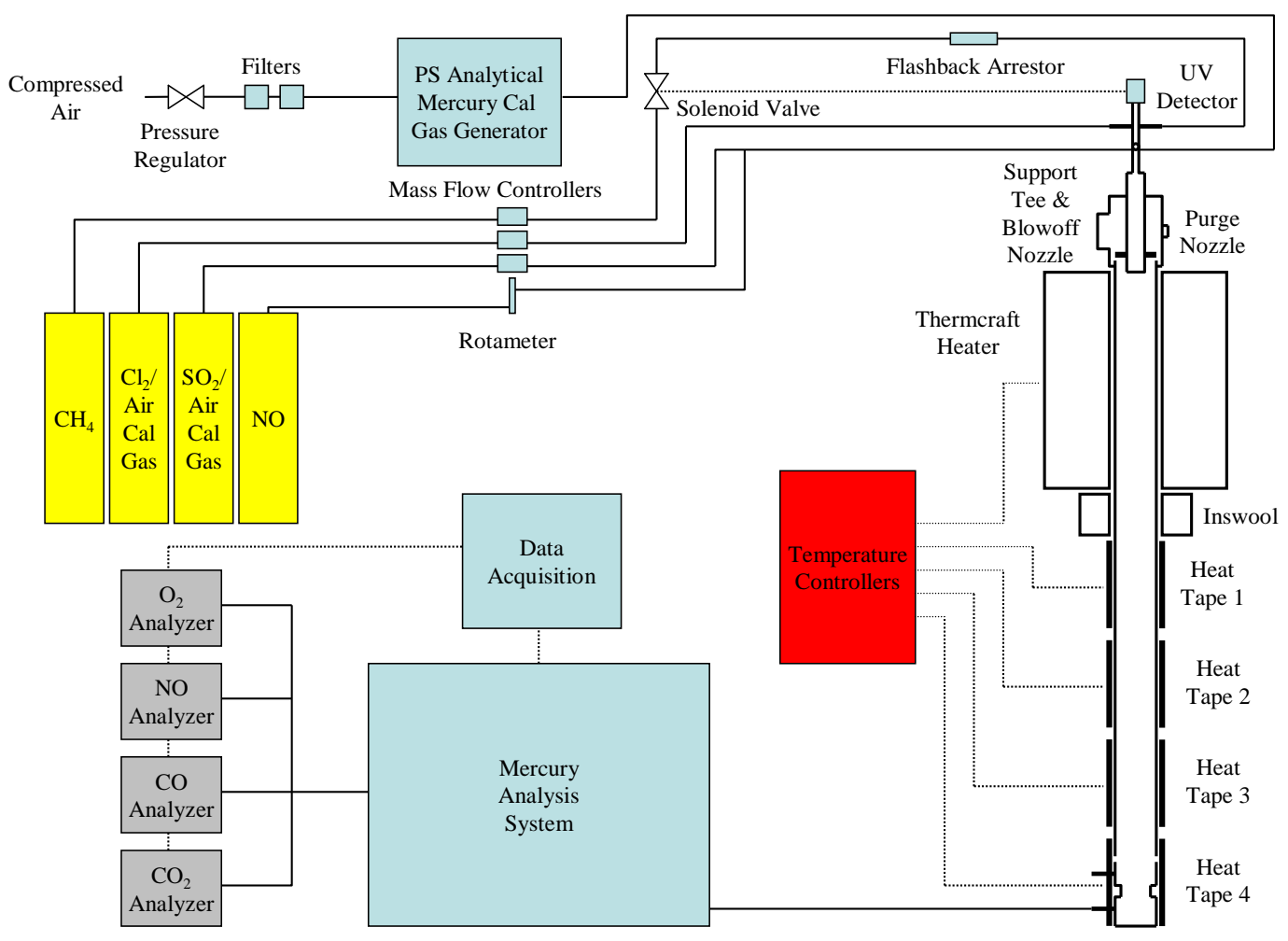

Figure 1. Sketch of the homogeneous mercury reactor ${ }^{9}$.

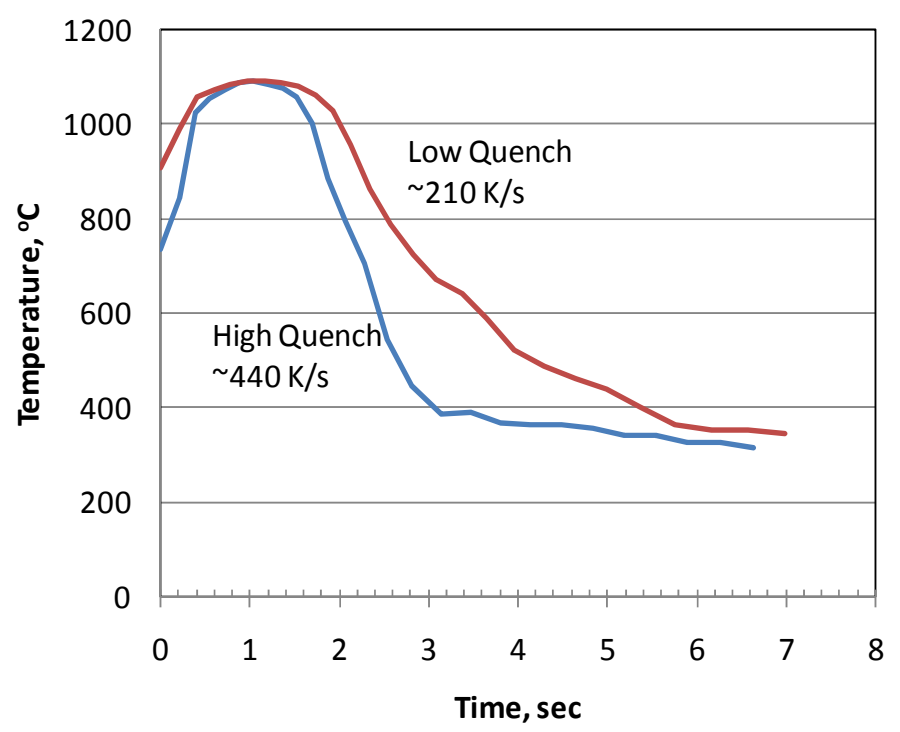

Figure 2. Temperature profiles in the homogeneous mercury reactor. 


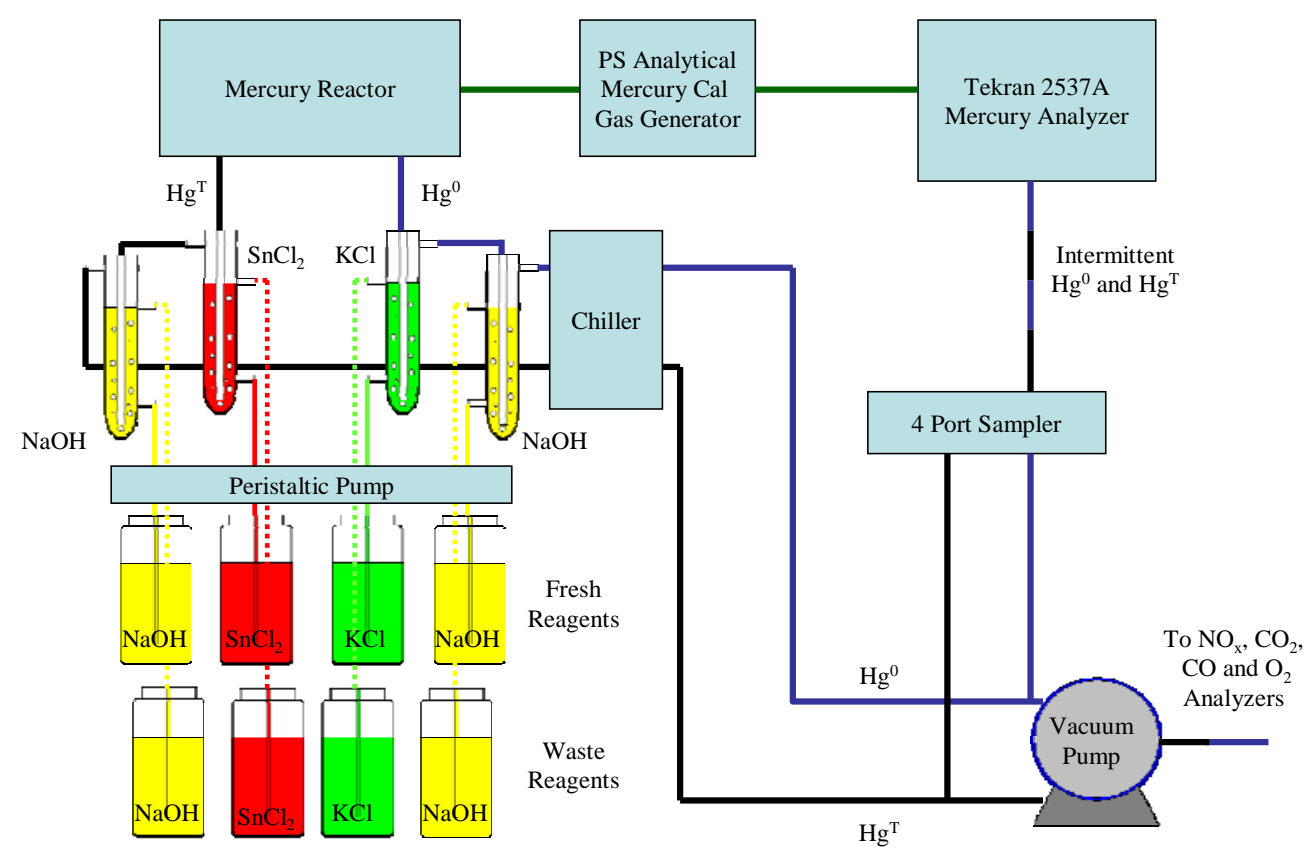

Figure 3. Mercury analysis system ${ }^{9}$.

Table 1. Flue Gas Compositions.

\begin{tabular}{|l|l|}
\hline Species & Concentration \\
\hline $\mathrm{O}_{2}$ & 0.8 vol\% \\
\hline $\mathrm{H}_{2} \mathrm{O}$ & $16.5 \mathrm{vol} \%$ \\
\hline $\mathrm{CO}_{2}$ & 7.7 vol\% \\
\hline $\mathrm{NO}$ & $30,500 \mathrm{ppmv}$ \\
\hline $\mathrm{SO}_{2}$ & $0-500 \mathrm{ppmv}$ \\
\hline $\mathrm{HCl}^{*}$ & $0-500 \mathrm{ppmv}$ \\
\hline $\mathrm{HBr}^{* *}$ & $0-50 \mathrm{ppmv}$ \\
\hline $\mathrm{Hg}^{0}$ & $\begin{array}{l}25 \mu \mathrm{g} / \mathrm{Nm}^{3}(1 \\
\left.\text { atm and } 0^{\circ} \mathrm{C}\right)\end{array}$ \\
\hline
\end{tabular}

*Assuming all chlorine added as $\mathrm{HCl}$

**Assuming all bromine added as $\mathrm{HBr}$ 


\section{RESULTS AND DISCUSSION}

\section{Effect of Impinger Chemistry}

We and other researchers have observed that the impinger solutions used in a wet conditioning system for measurement of mercury via a CEM can affect the concentrations of total and elemental mercury as reported by the CEM. Previously, we corrected a bias in the measurement of elemental mercury when chlorine was added through the burner as an oxidant for mercury. ${ }^{11}$

Benson et al. ${ }^{10}$ noted that total mercury measurements were biased low when bromine was added to the combustion system in a coal-fired power plant. In the laboratory reactor, the same effect was noted. Figure 4 illustrates this point with CEM data from an

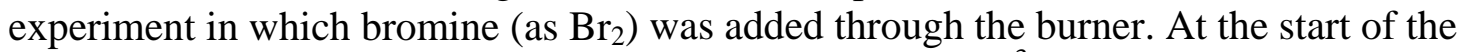
experiment, the total mercury at the reactor exit is $\sim 25 \mu \mathrm{g} / \mathrm{m}^{3}$. There is no net oxidation of mercury across the reactor, so the elemental mercury is equal to the total mercury. When bromine is added through the burner, the total and elemental mercury concentrations quickly decrease, but recover once the bromine is turned off. The decrease in total mercury increases as bromine concentration is increased. Similar decreases in the total mercury were not observed in parallel tests with chlorine.

In order to explore this bias in the measurement of total mercury when bromine was used, the compositions of the solutions on the total side of the conditioning system were modified. For these experiments, the bromine concentration was $50 \mathrm{ppmv}$ (as $\mathrm{HBr}$ equivalent), the $\mathrm{NO}$ concentration was $\sim 30 \mathrm{ppmv}$, and the total $\mathrm{Hg}$ concentration entering the reactor was $25 \mu \mathrm{g} / \mathrm{m}^{3}$. The usual configuration for the total side was an impinger containing $5 \mathrm{wt} \% \mathrm{SnCl}_{2}$ and $3 \mathrm{wt} \% \mathrm{HCl}$ in water, followed by an impinger containing $\mathrm{NaOH}$. The solution in the first impinger was modified or, in some cases, additional impingers were added to improve the reduction from total to elemental mercury. The results of these modifications are shown in Figures 5, 6, and 7, each examining a different factor: (1) different concentrations of the $\mathrm{SnCl}_{2}-\mathrm{HCl}$ solution in Figure 5, (2) additional $\mathrm{NaOH}$ impingers on the total side of the conditioning system in Figure 6, and (3) the use of a hydroxylamine hydrochloride-sodium hydroxide $\left(\mathrm{NH}_{2} \mathrm{OH} * \mathrm{HCl}-\mathrm{NaOH}\right)$ solution instead of the $\mathrm{SnCl}_{2}-\mathrm{HCl}$ solution in Figure 7. In all cases, the $\mathrm{SnCl}_{2}-\mathrm{HCl}$ or the $\mathrm{NH}_{2} \mathrm{OH}^{*} \mathrm{HCl}-\mathrm{NaOH}$ impinger was followed by a 5 wt \% $\mathrm{NaOH}$ impinger. 


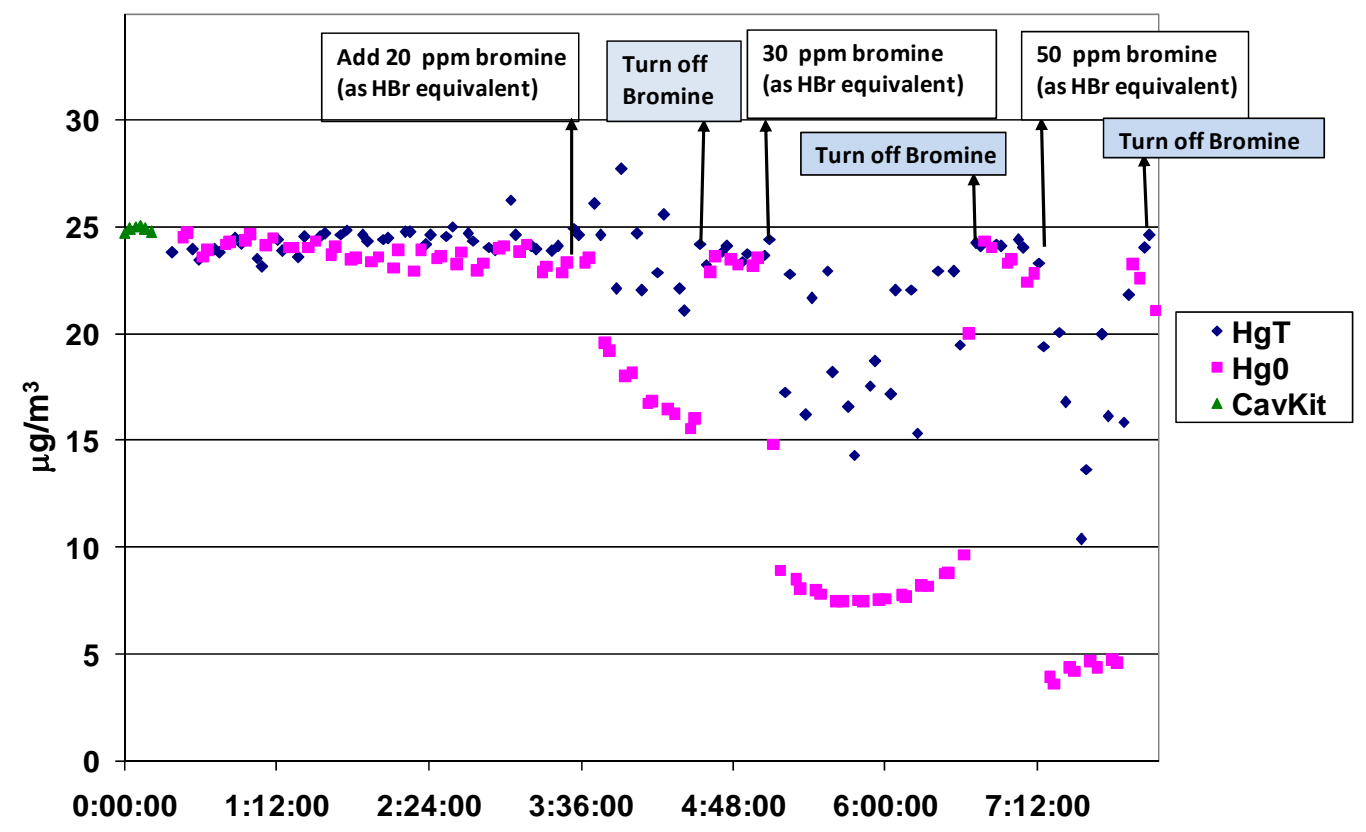

Figure 4. Measured total (HgT) and elemental mercury (Hg0) versus time, with and without bromine injection through the burner, obtained with the high quench temperature profile. The total mercury concentration should be constant at $25 \mu \mathrm{g} / \mathrm{m}^{3}$.

Figure 5 shows the measured decrease in total mercury with concentrations of $\mathrm{SnCl}_{2}-\mathrm{HCl}$ ranging from 3 to $10 \mathrm{wt}$. percent. The decreases in total mercury were calculated using the difference between the total side value and the baseline concentration of $25 \mu \mathrm{g} / \mathrm{m}^{3}$. No $\mathrm{SO}_{2}$ was added to the reactor and there was $30 \mathrm{ppmv} \mathrm{NO}$ and $50 \mathrm{ppmv}$ bromine (as $\mathrm{HBr}$ equivalent). Figure 5 shows that none of the conditions tested caused a significant improvement in the total mercury concentration. In an ideal conditioning system, there would be no decrease in total mercury. 


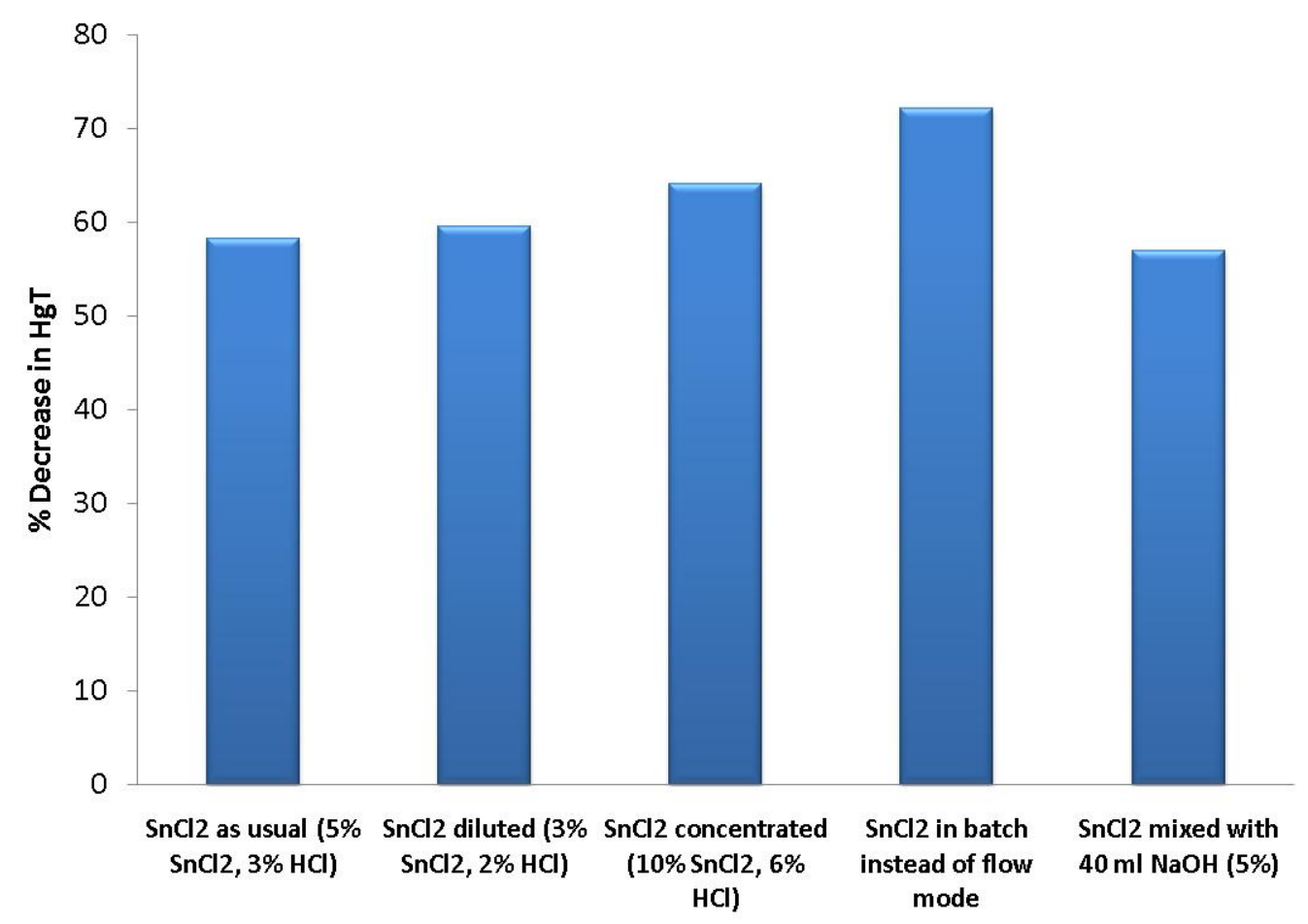

Figure 5. Losses in total mercury when using different concentrations of the $\mathrm{SnCl}_{2}-\mathrm{HCl}$ solution on the total mercury side of the sample conditioning system with $50 \mathrm{ppmv}$ bromine (as $\mathrm{HBr}$ equivalent), $30 \mathrm{ppmv} \mathrm{NO}$, and the high quench temperature profile.

Figure 6 shows the decrease in total mercury concentration when additional $\mathrm{NaOH}$ impingers were installed before the $\mathrm{SnCl}_{2}-\mathrm{HCl}$ impinger. It was hoped that the additional $\mathrm{NaOH}$ impinger would remove $\mathrm{Br}_{2}$ before it reached the $\mathrm{SnCl}_{2}$ impinger by the reaction

$$
\mathrm{Br}_{2}+2 \mathrm{NaOH}=\mathrm{NaBr}+\mathrm{NaOBr}+\mathrm{H}_{2} \mathrm{O} \text {, }
$$

and possibly help promote the reduction of $\mathrm{HgBr}_{2}$ to $\mathrm{Hg}^{0}$ in the downstream $\mathrm{SnCl}_{2}$ impinger. The decrease in total mercury concentration in Figure 6 was calculated using the difference between the total side value and the baseline concentration of $25 \mu \mathrm{g} / \mathrm{m}^{3}$. No $\mathrm{SO}_{2}$ was added to the reactor and there was 30 ppmv NO and 50 ppmv bromine (as $\mathrm{HBr}$ equivalent). The decrease in the total mercury concentration obtained with the use of additional $\mathrm{NaOH}$ impingers is greater than those shown in Figure 5, although this may be partly due to scatter in the data. 


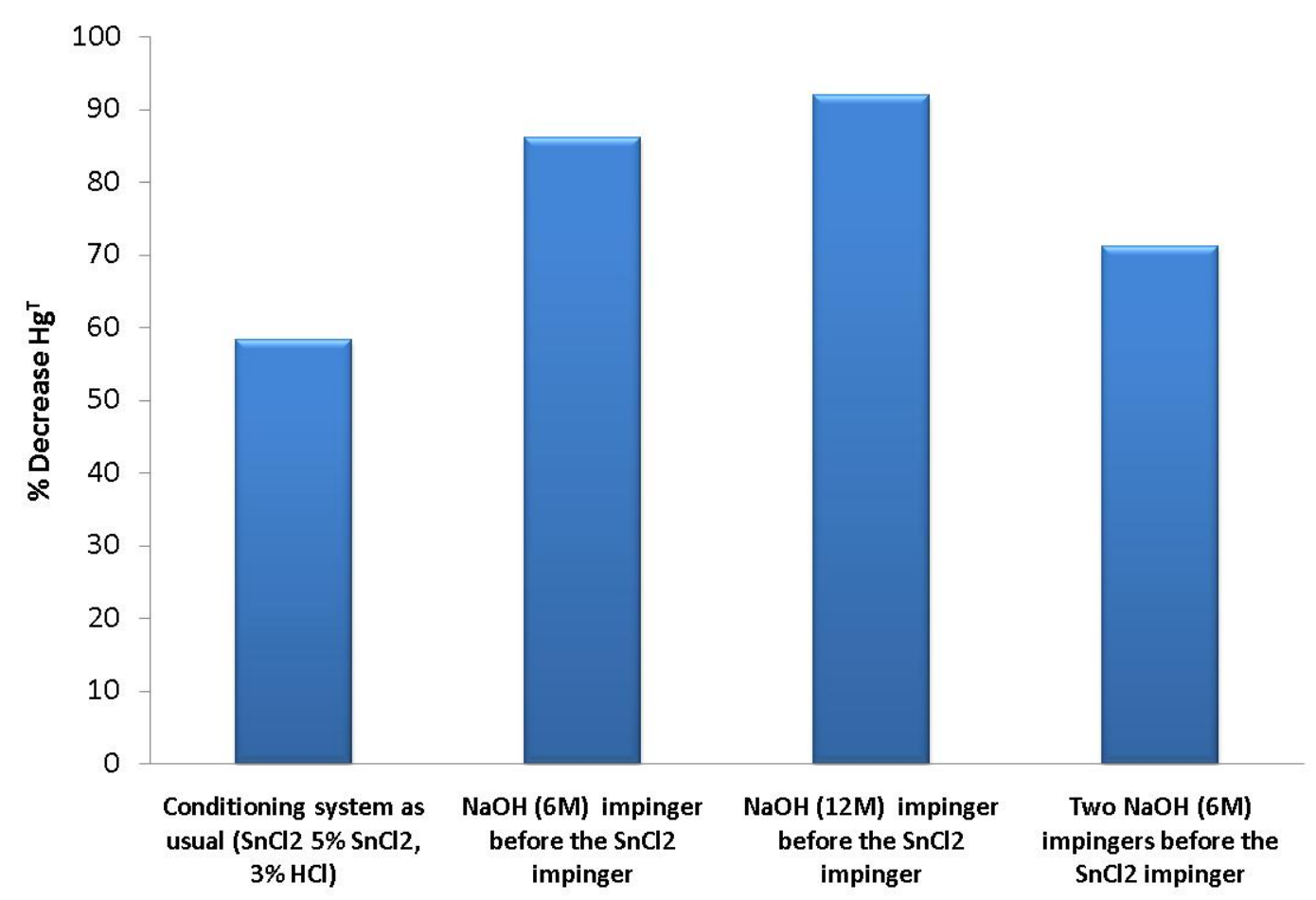

Figure 6. Losses in total mercury when using additional $\mathrm{NaOH}$ impingers on the total mercury side of the sample conditioning systems with $50 \mathrm{ppmv}$ bromine (as $\mathrm{HBr}$ equivalent), $30 \mathrm{ppmv} \mathrm{NO}$, and the high quench temperature profile.

Figure 7 shows the measured decrease in total mercury concentration with $50 \mathrm{ppm}$ bromine (as $\mathrm{HBr}$ equivalent), when different mixtures of $\mathrm{NH}_{2} \mathrm{OH}^{*} \mathrm{HCl}$ and $\mathrm{NaOH}$ were used instead of the standard $\mathrm{SnCl}_{2}-\mathrm{HCl}$ solution. Hydroxyl amine hydrochloride has been used for mercury concentration measurements with urine, blood, and hair samples ${ }^{12,13,14}$, mostly as an stabilizing agent. It is also a commonly used reducing agent for various applications in synthetic and analytical chemistry.

The decrease in total mercury concentration shown in Figure 7 was calculated using the difference between the total side value and the baseline concentration of $25 \mu \mathrm{g} / \mathrm{m}^{3}$. No $\mathrm{SO}_{2}$ was added to the reactor and there was $30 \mathrm{ppmv}$ NO. As shown by the figure, the use of a solution $4 \mathrm{wt} \% \mathrm{NH}_{2} \mathrm{OH} * \mathrm{HCl}$ and $20 \mathrm{wt} \% \mathrm{NaOH}$ allowed the measurement of total mercury concentration with a decrease of just 15 percent. The stability of the total mercury levels was observed for periods of 2 hours; after 2 hours, the total levels started to decrease. This decrease could be due to deposition of mercury on the reactor and impinger walls. The presence or absence of a $\mathrm{NaOH}$ impinger after the $\mathrm{NH}_{2} \mathrm{OH} * \mathrm{HCl}-$ $\mathrm{NaOH}$ impinger did not make any difference in the measured total mercury concentrations. Based on these encouraging results, a solution of $4 \mathrm{wt} \% \mathrm{NH}_{2} \mathrm{OH}^{*} \mathrm{HCl}$ 
and 20 wt \% $\mathrm{NaOH}$ was used for all subsequent experiments in which bromine was present in the system.

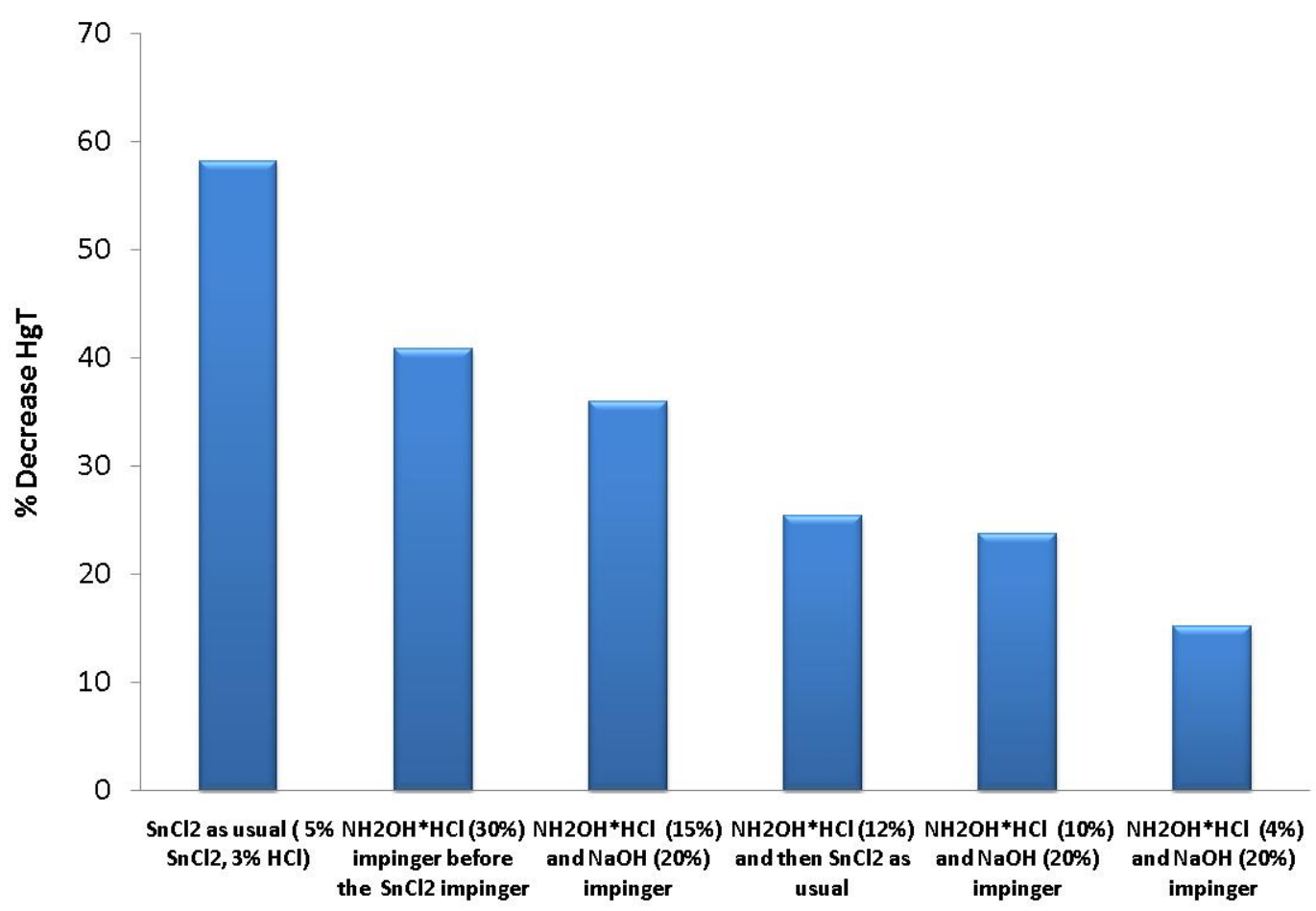

Figure 7. Losses in total mercury using a solution of $\mathrm{NH}_{2} \mathrm{OH}^{*} \mathrm{HCl}-\mathrm{NaOH}$ instead of $\mathrm{SnCl}_{2}-\mathrm{HCl}$ on the total mercury side of the sample conditioning system with $50 \mathrm{ppmv}$ bromine (as $\mathrm{HBr}$ equivalent), $30 \mathrm{ppmv} \mathrm{NO}$, and the high quench temperature profile.

We also observed a bias on the elemental side of the measurement system when chlorine was added as an oxidant and no $\mathrm{SO}_{2}$ was present. This bias was eliminated for chlorine by using an impinger solution consisting of $10 \mathrm{wt} \% \mathrm{KCl}$ and $0.5 \mathrm{wt} \%$ sodium thiosulfate in water, followed by an impinger containing $\mathrm{NaOH}$. In order to test for this bias when using bromine, experiments were performed in which the compositions of the solutions on the elemental side of the conditioning system were varied. For these experiments, the bromine concentration was $50 \mathrm{ppmv}$ ( $\mathrm{HBr}$ equivalent), the $\mathrm{NO}$ concentration was 30 $\mathrm{ppm}$, and the total $\mathrm{Hg}$ concentration entering the reactor was $25 \mu \mathrm{g} / \mathrm{m}^{3}$. The default configuration for the elemental side was an impinger containing $10 \mathrm{wt} \% \mathrm{KCl}$ and $0.5 \mathrm{wt} \%$ sodium thiosulfate in water, followed by an impinger containing $\mathrm{NaOH}$. The solution in the first impinger was modified or, in one case, the first impinger was eliminated and only the $\mathrm{NaOH}$ impinger was used on the elemental mercury side. 
The solutions in the first impinger included (1) the standard configuration of $10 \mathrm{wt} \% \mathrm{KCl}$ and $0.5 \mathrm{wt} \%$ sodium thiosulfate in water, followed by an impinger $5 \mathrm{wt} \% \mathrm{NaOH}$; (2) the standard configuration without the sodium thiosulfate; (3) replacement of the $\mathrm{KCl}$ and sodium thiosulfate with $12 \mathrm{wt} \%$ of tris (hydroxymethyl) aminomethane (THAM) and 0.3 wt \% ethylenediamine tetra acetic acid (EDTA); and (4) a single impinger containing 5 wt \% sodium hydroxide.

Figure 8 shows the measured decrease in elemental mercury, calculated from the elemental mercury reported by the CEM and the baseline elemental mercury concentration of $25 \mu \mathrm{g} / \mathrm{m}^{3}$. The composition of the impinger solutions used here does not significantly affect the measured mercury speciation when bromine is added to the reactor in the absence of $\mathrm{SO}_{2}$.

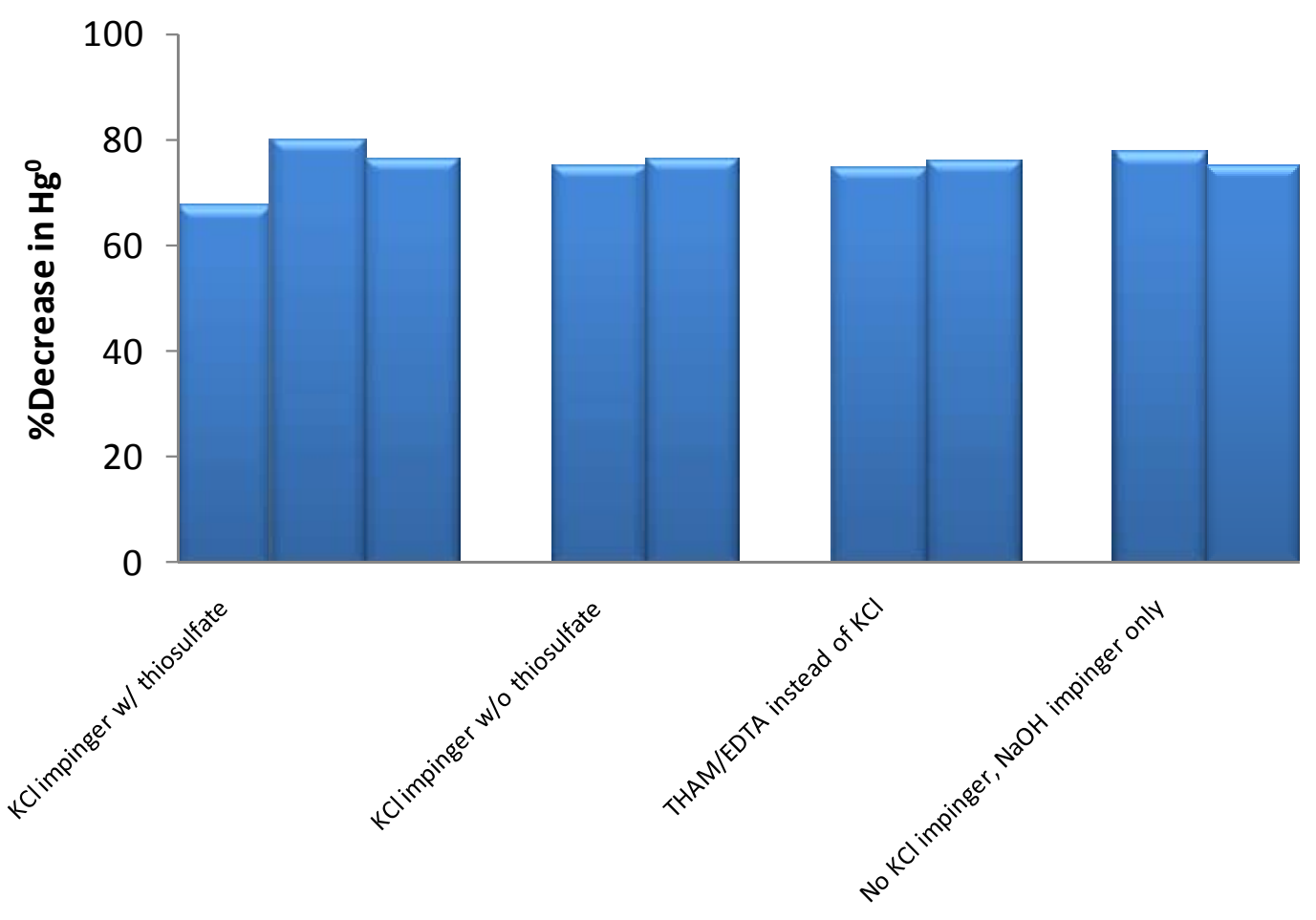

Figure 8. Decrease in elemental mercury using different impinger solutions on the elemental mercury side of the sample conditioning system with 50 ppmv bromine (as $\mathrm{HBr}$ equivalent), $30 \mathrm{ppmv} \mathrm{NO}$, and the high quench temperature profile.

The elemental side of the conditioning system was also modified by the addition of one impinger or, in some cases, a packed bed of $\mathrm{NaOH}$ to study the apparent inhibition of mercury oxidation by bromine in the presence of $\mathrm{SO}_{2}$. The default configuration for the 
elemental side was an impinger containing $10 \mathrm{wt} \% \mathrm{KCl}$ and $0.5 \mathrm{wt} \%$ sodium thiosulfate in water, followed by an impinger containing $\mathrm{NaOH}$. The modifications included (1) an additional impinger of $5 \mathrm{wt} \% \mathrm{NaOH}$ solution before the $\mathrm{KCl}$ impinger in the standard configuration and (2) a bed with 40 grams of $\mathrm{NaOH}$ pellets heated to $120^{\circ} \mathrm{C}$ before the $\mathrm{KCl}$ impinger in the standard configuration. The objective of these modifications was to remove the $\mathrm{SO}_{2}$ before it reached the $\mathrm{KCl}$ impinger and thus prevent liquid-phase inhibition of mercury oxidation by bromine in the presence of $\mathrm{SO}_{2}$.

Figure 9 shows the effect of $\mathrm{SO}_{2}$ on mercury oxidation by bromine with two different configurations of the elemental-side conditioning system: the usual configuration and one in which an additional $\mathrm{NaOH}$ impinger was incorporated before the $\mathrm{KCl}$ impinger. As shown in Figure 9, at $\mathrm{SO}_{2}$ concentrations higher than $200 \mathrm{ppm}$, there is no effect of $\mathrm{SO}_{2}$ on mercury oxidation by bromine; however, the addition of either $50 \mathrm{ppm}$ or $100 \mathrm{ppm}$ $\mathrm{SO}_{2}$ causes a significant reduction in the extent of oxidation. The magnitude of the change is tempered by the addition of the $\mathrm{NaOH}$ impinger in front of the $\mathrm{KCl}$ impinger. It was hoped that the additional $\mathrm{NaOH}$ impinger would remove $\mathrm{SO}_{2}$ from the sample stream and possibly prevent the reduction of oxidized mercury by $\mathrm{SO}_{2}$ in the $\mathrm{KCl}$ impinger. Figure 9 suggests that the additional $\mathrm{NaOH}$ impinger may be having this effect, at least at lower $\mathrm{SO}_{2}$ levels. 


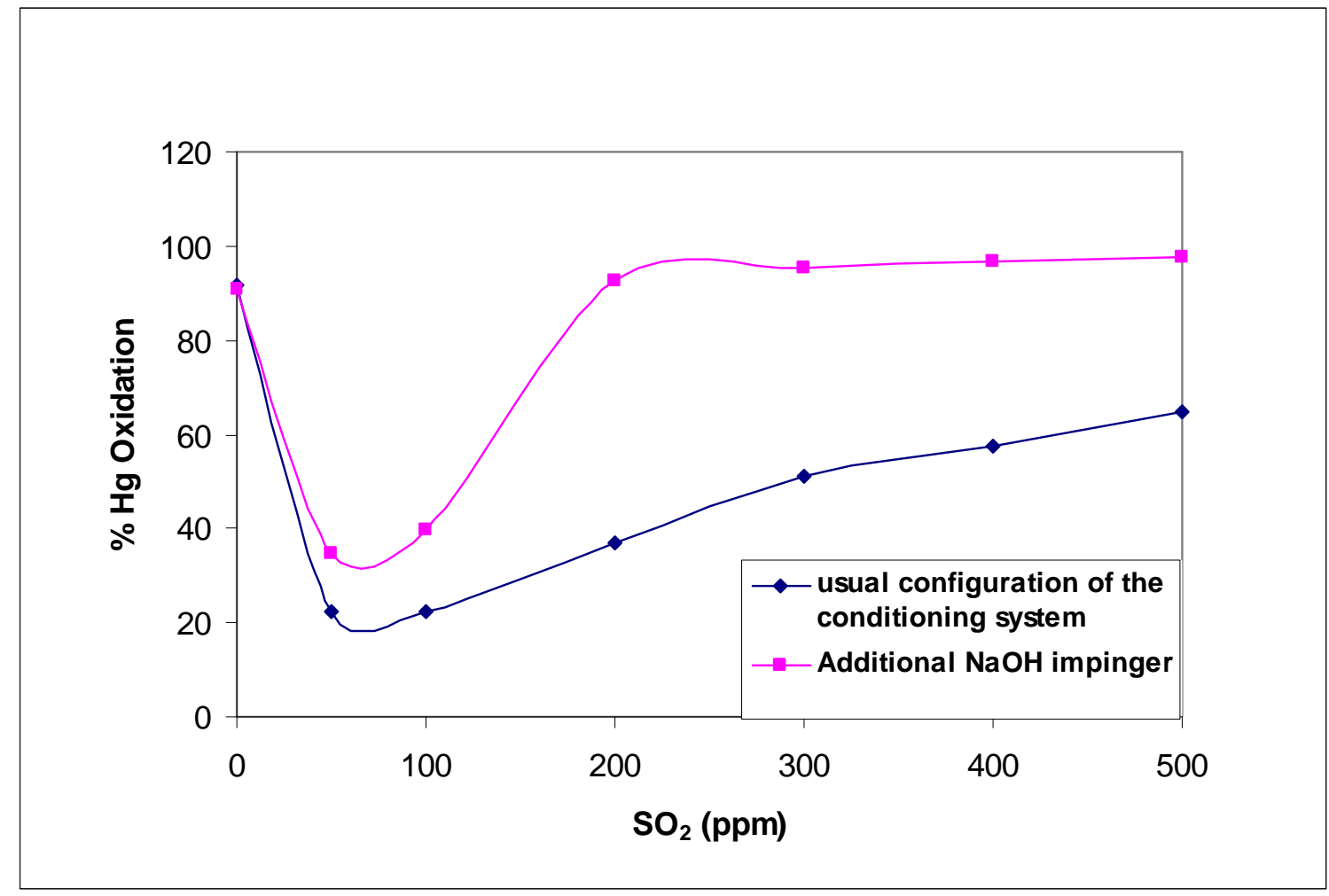

Figure 9. Effect of $\mathrm{SO}_{2}$ on mercury oxidation by bromine with and without an additional $\mathrm{NaOH}$ impinger before the $\mathrm{KCl}$ impinger on the elemental side of the conditioning system at 50 ppmv bromine (as $\mathrm{HBr}$ equivalent), $30 \mathrm{ppmv} \mathrm{NO}$, and with the high quench temperature profile.

Because liquid-phase reactions appear to be responsible for the effects seen in Figure 9, the $\mathrm{SO}_{2}$-scrubbing, $\mathrm{NaOH}$ impinger was replaced with a heated bed of 40 grams of $\mathrm{NaOH}$ pellets at $120^{\circ} \mathrm{C}$. As shown in Figure 10, the apparent inhibitory effect of $\mathrm{SO}_{2}$ on mercury oxidation by bromine is still observed and is similar to that shown in Figure 9. Additional experiments are planned to measure $\mathrm{SO}_{2}$ levels before the $\mathrm{KCl}$ impinger in order to determine the effectiveness of the $\mathrm{NaOH}$ bed and impinger at removing $\mathrm{SO}_{2}$. 


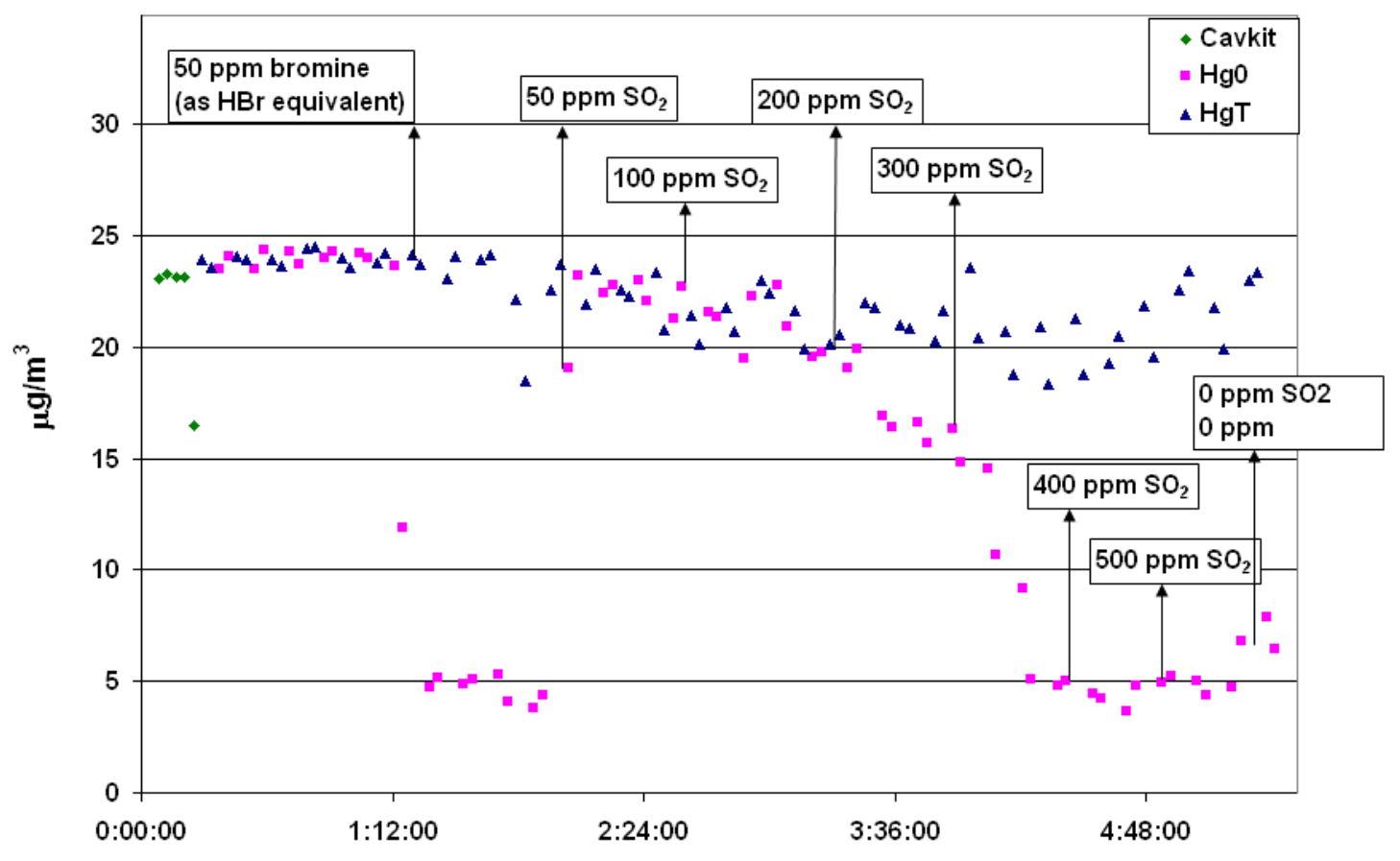

Figure 10. Effect of $\mathrm{SO}_{2}$ on mercury oxidation by bromine using a packed bed of $\mathrm{NaOH}$ pellets at $120^{\circ} \mathrm{C}$ before the $\mathrm{KCl}$ impinger on the elemental side of the conditioning system. The reactor conditions were $50 \mathrm{ppmv}$ bromine (as $\mathrm{HBr}$ equivalent), $30 \mathrm{ppmv} \mathrm{NO}$, and high quench temperature profile.

\section{Effects of Mixtures of Bromine and Chlorine on Homogeneous Oxidation}

Bromine is a more powerful oxidant than chlorine, on an equivalent molar basis. This has been observed in full-scale power-plant trials ${ }^{10,15}$ and can be seen in the laboratory data in Figure 11 that were obtained at the high and low quench rates. No $\mathrm{NO}$ or $\mathrm{SO}_{2}$ was added to the burner in these experiments, although the methane flame produced approximately 30 ppmv NO. Little or no effect of quench rate was noted.

Cao et al. ${ }^{16,17}$ suggested that the simultaneous presence of bromine and chlorine can also affect the extent of mercury oxidation due to interhalogen species interactions with elemental mercury. Based on experimental oxidation levels that were higher than expected, they suggested that bromine is able to increase mercury oxidation kinetics by promoting the formation of activated chlorine. We performed experiments to study the combined effect of bromine and chlorine on mercury oxidation and typical results obtained at the high quench rate are summarized in Figure 12. There is a slight increase 
in mercury oxidation in the presence of chlorine at either 100 or 400 ppmv. The increase is roughly proportional to the concentration of chlorine in the system.

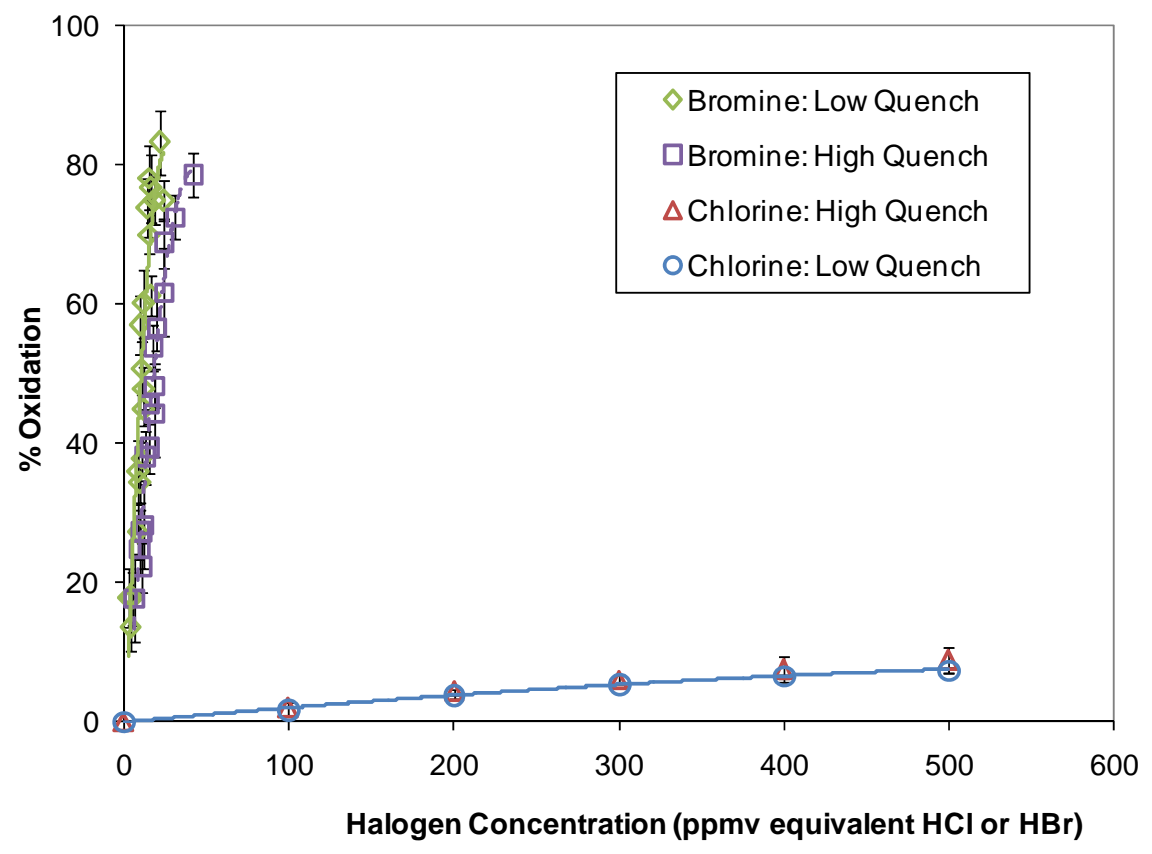

Figure 11. Homogeneous mercury oxidation with the addition of chlorine or bromine, 30 ppmv NO at high and low quench rates. 


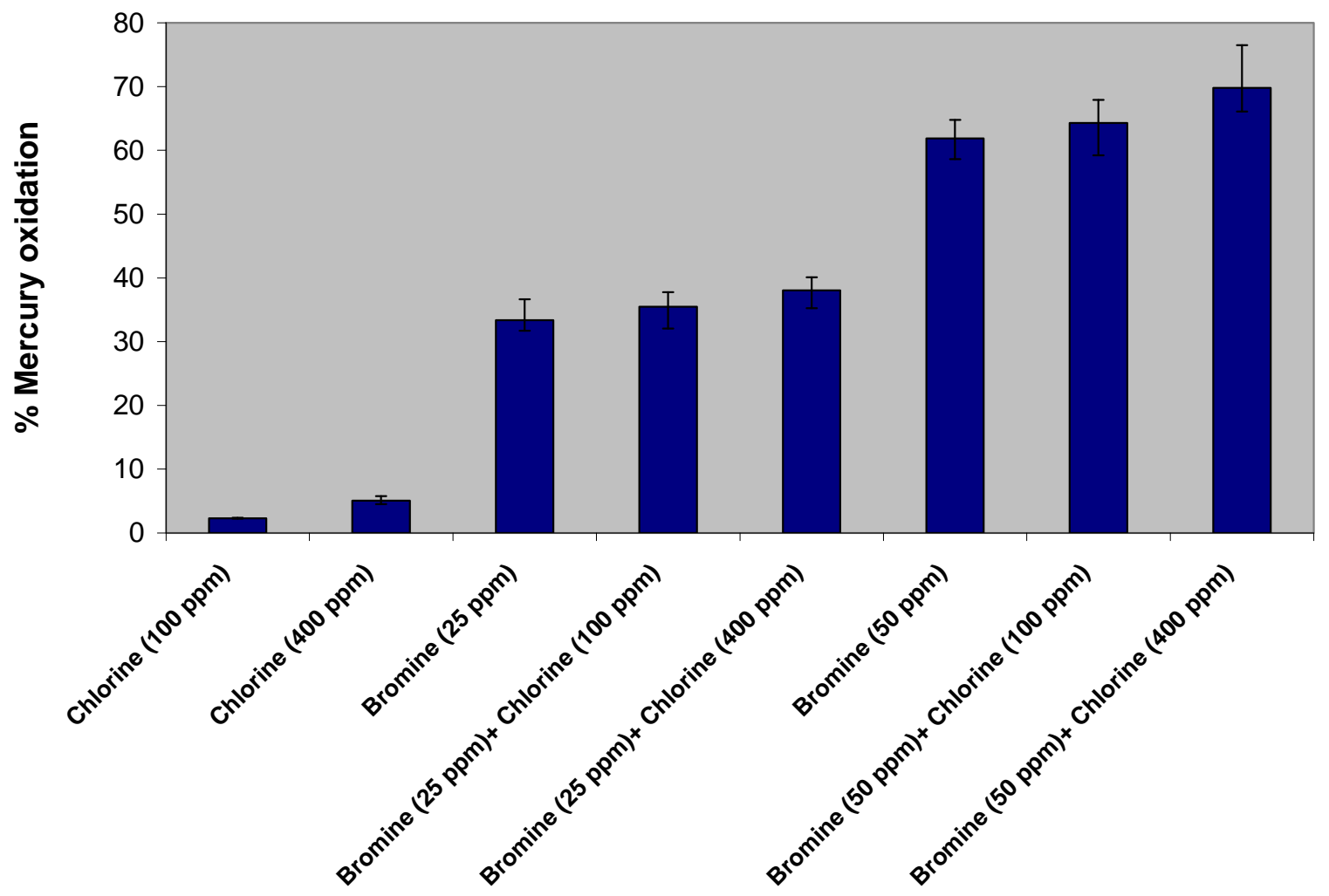

Figure 12. Homogeneous mercury oxidation at various concentrations of chlorine and bromine and 30 ppmv NO. The high quench temperature profile was used.

\section{Effect of Quench Rate}

The quench rate in the post-flame region affects the concentrations of free radicals, like $\mathrm{Cl}$ or $\mathrm{Br}$, that are thought to initiate oxidation of $\mathrm{Hg}^{0}$ in the gas-phase. ${ }^{18}$ The effect of quench rate is illustrated in Figures 13 and 14, for oxidation by chlorine and bromine. For chlorine the differences are slight and highly uncertain, given the low levels of oxidation and the experimental uncertainties. Reaction with bromine produces significantly more oxidation of mercury at the lower quench rate than at the higher. 


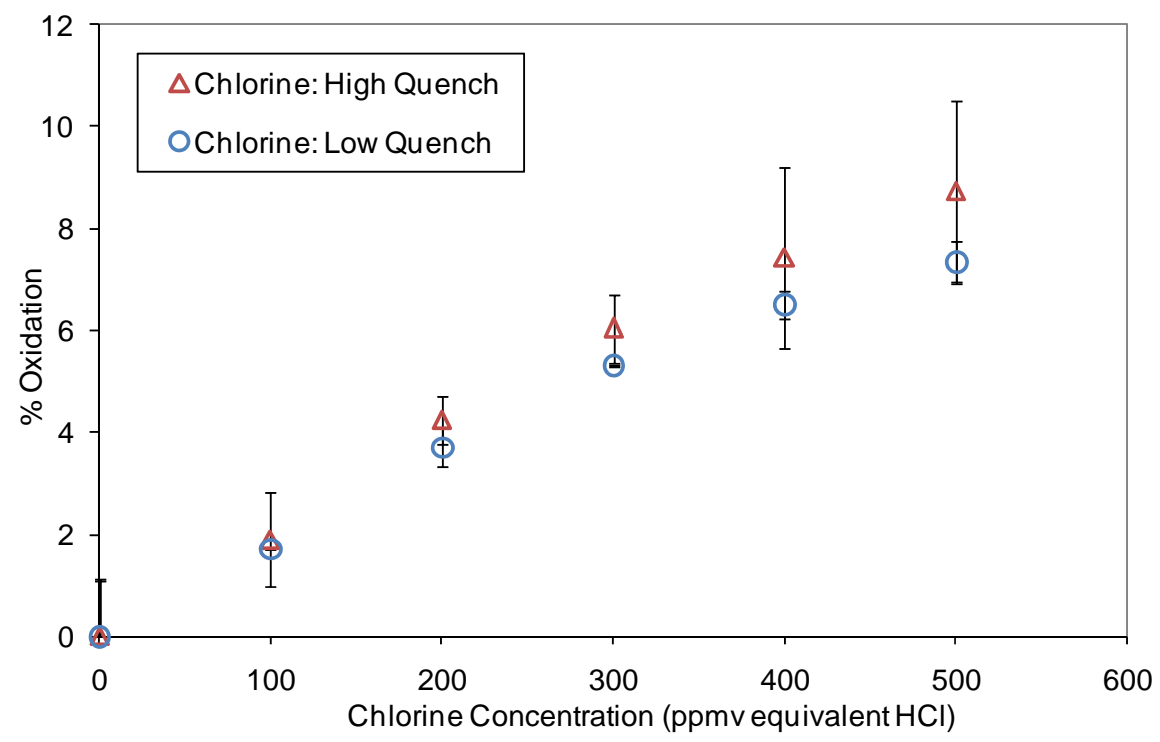

Figure 13. Oxidation of mercury by chlorine as a function of quench rate with $30 \mathrm{ppmv}$ NO.

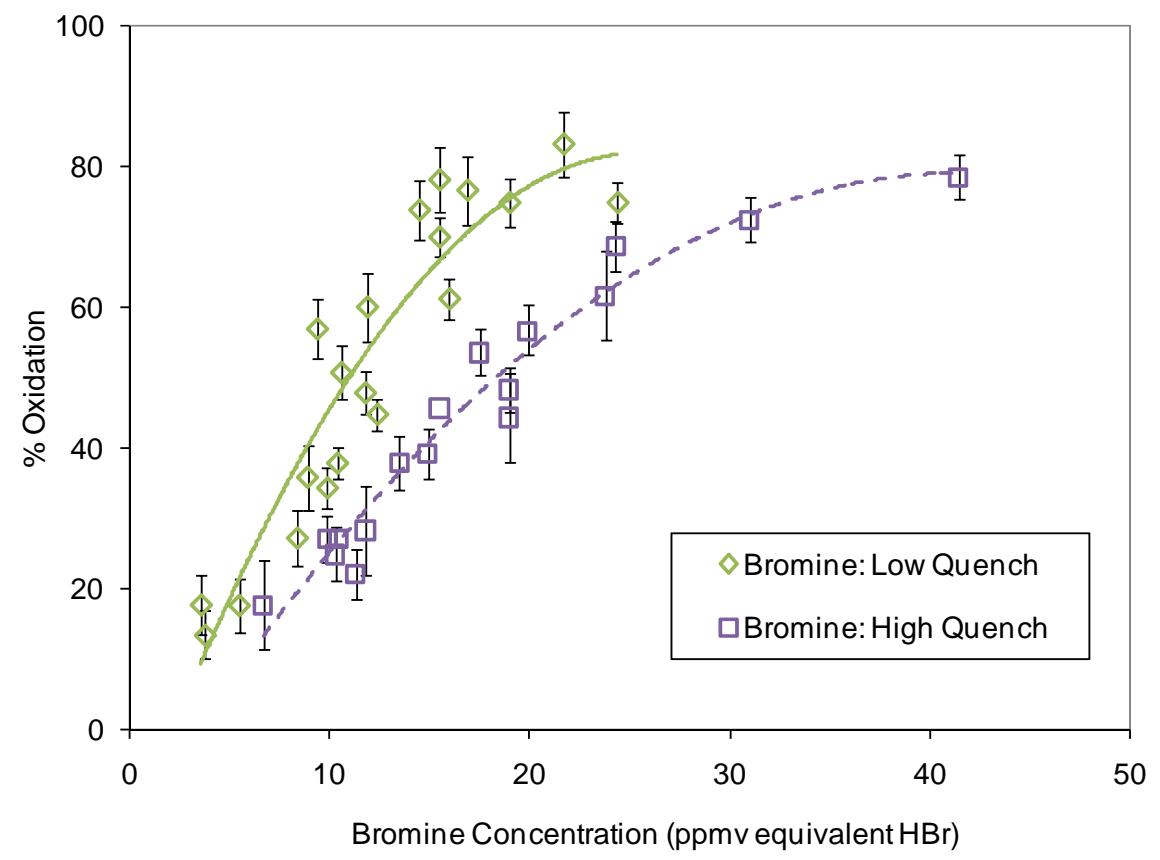

Figure 14. Oxidation of mercury by bromine as a function of quench rate with $30 \mathrm{ppmv}$ NO. 
The quench rate also changes the relative importance of chlorine when both bromine and chlorine are present. Figure 15 shows the results of six experiments that were conducted with $25 \mathrm{ppm}$ bromine (as $\mathrm{HBr}$ equivalent) and chlorine concentrations ranging from zero to $400 \mathrm{ppm}$ (as $\mathrm{HCl}$ equivalent). The increase in oxidation that can be attributed to the chlorine is more pronounced for the low quench profile than for the high.
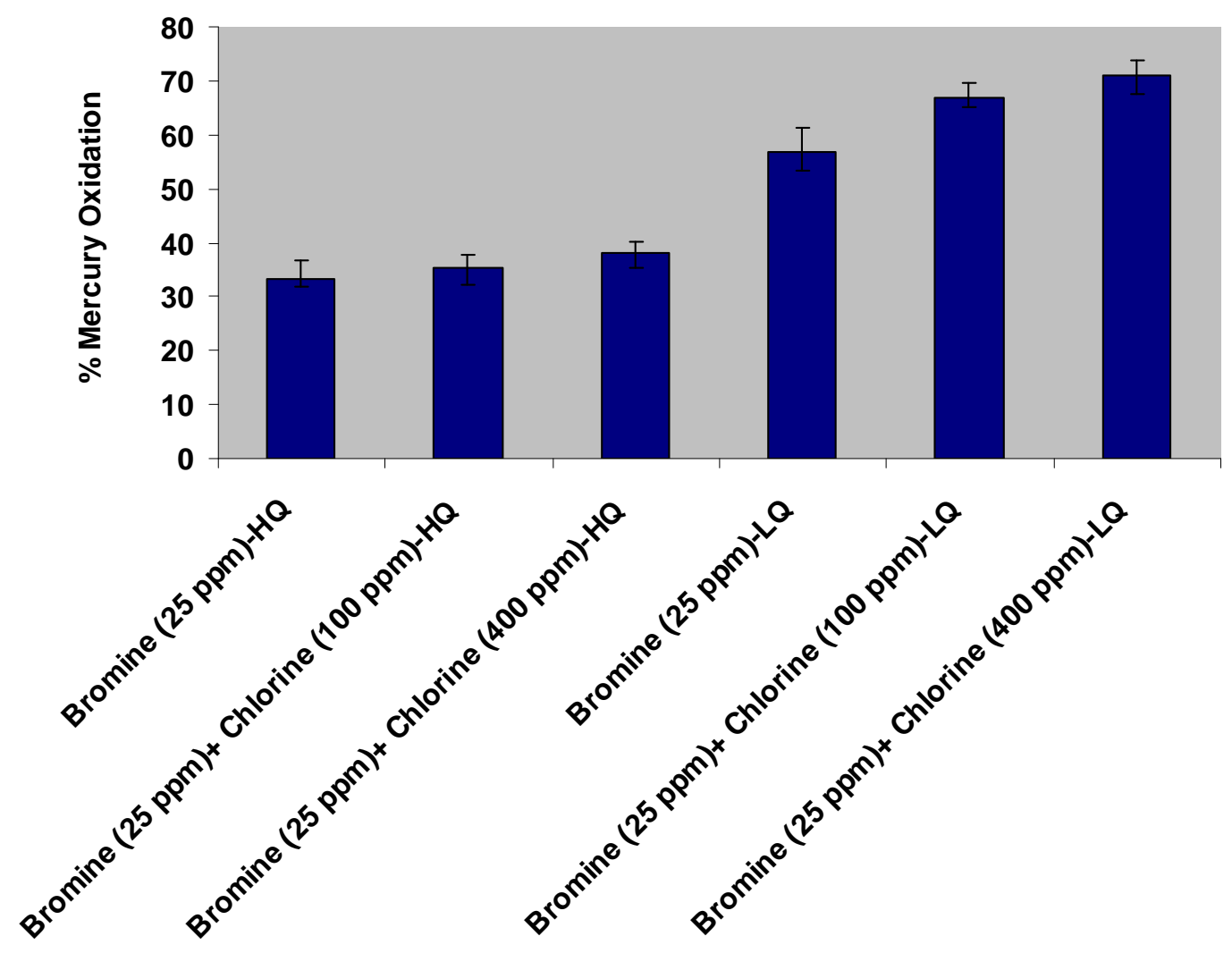

Figure 15. Oxidation of mercury by bromine and chlorine as a function of quench rate and chlorine concentration with $30 \mathrm{ppmv} \mathrm{NO}$ and a constant bromine concentration of 25 ppm (as $\mathrm{HBr}$ equivalent).

\section{Effect of Acid Gas Species}

In coal-fired power plants, $\mathrm{NO}_{\mathrm{x}}$ concentrations can be in the range of 50 to $1000 \mathrm{ppmv}$, depending on the type of $\mathrm{NO}_{\mathrm{x}}$ control system employed. Nitrogen oxides typically 
consists of $5-10 \% \mathrm{NO}_{2}$ with the balance NO. The laboratory reactor produces about 30 ppmv $\mathrm{NO}_{\mathrm{x}}$ (of which most is $\mathrm{NO}$ ). In some experiments, additional $\mathrm{NO}$ was added through the burner, to produce up to 500 ppmv $\mathrm{NO}_{\mathrm{x}}$ (again, mostly $\mathrm{NO}$ ). $\mathrm{SO}_{2}$ concentrations in coal-fired power plants vary widely from $300 \mathrm{ppmv}$ up to 3,000 ppmv. In the laboratory reactor, up to 500 ppmv $\mathrm{SO}_{2}$ was added, by injecting $\mathrm{SO}_{2}$ through the methane-fired burner.

Figure 16 shows the effect of $\mathrm{NO}$ and $\mathrm{SO}_{2}$ on mercury oxidation by chlorine. Increasing the NO concentration from 30 ppmv to 500 ppmv had little or no effect on mercury oxidation by chlorine, within experimental error. Adding $\mathrm{SO}_{2}$ at $400 \mathrm{ppmv}$ did not affect mercury oxidation by chlorine when the chlorine concentration was $300 \mathrm{ppmv}$ (equivalent $\mathrm{HCl}$ ) or less. However, at concentrations greater than $400 \mathrm{ppmv} \mathrm{HCl}$, there was an increase in mercury oxidation with the addition of $\mathrm{SO}_{2}$.

Smith et al. ${ }^{4}$ observed inhibition or enhancement of mercury oxidation by chlorine when $\mathrm{SO}_{2}$ was added to a laboratory methane-fired furnace; the effect depended on the concentrations of $\mathrm{SO}_{2}$ and $\mathrm{HCl}$. There was little effect of $\mathrm{SO}_{2}$ at $400 \mathrm{ppmv} \mathrm{SO}_{2}$, up to 550 ppmv HCl. However, at lower concentrations of $\mathrm{SO}_{2}$ (100-200 ppmv), Smith reports that $\mathrm{SO}_{2}$ did have an effect on the level oxidation.

The results in Figure 17 show that the addition of NO did not affect oxidation by bromine. This agrees with the results shown for chlorine in Figure 16.

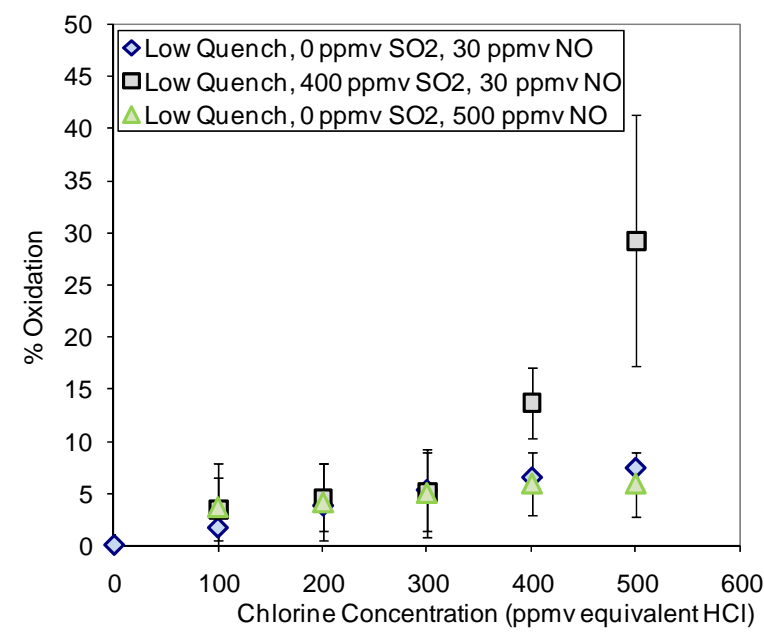

(a)

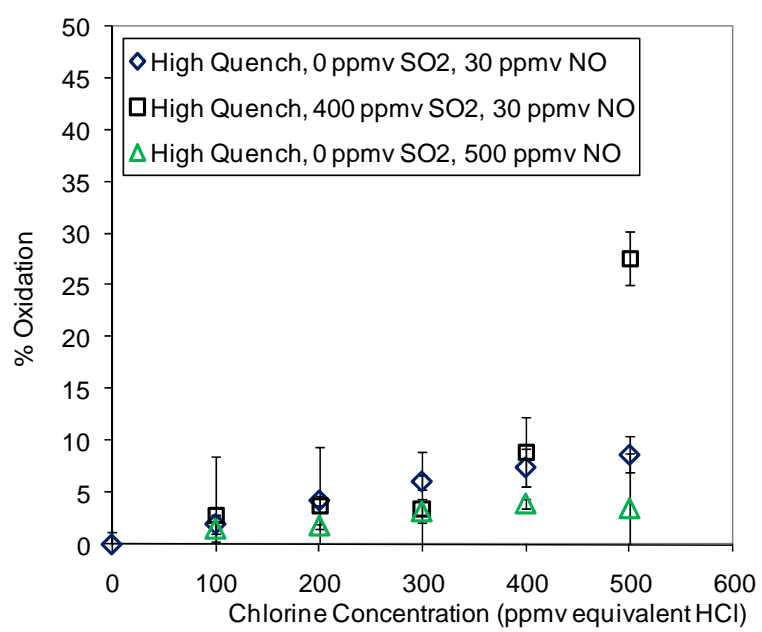

(b)

Figure 16. Effect of $\mathrm{SO}_{2}$ and $\mathrm{NO}$ on mercury oxidation by chlorine: (a) low quench rate; (b) high quench rate.

Discerning the effects of $\mathrm{SO}_{2}$ on the oxidation of mercury by bromine were complicated by impinger chemistry. For example, Wang et al. ${ }^{19}$ suggests that, under atmospheric 
conditions, elemental mercury can be oxidized by bromine in the aqueous phase, the extent of the oxidation depending on the $\mathrm{pH}$. The $\mathrm{pH}$ determines the predominant bromine species in the solution. It has been also proposed ${ }^{20,21,22,23,24}$ that some of the mercury oxidized by bromine can be reduced to the elemental state by species derived from $\mathrm{SO}_{2}$ in the aqueous solution. To study these liquid-phase interactions and the overall effect of $\mathrm{SO}_{2}$ on mercury oxidation by bromine, several experiments were performed with $\mathrm{SO}_{2}$ injected through the burner and through the impinger on the elemental side of the conditioning system. The $\mathrm{SO}_{2}$ concentration at different points along the reactor and conditioning system was also measured to better understand the fate of $\mathrm{SO}_{2}$.

Figure 18 shows the measured values of mercury oxidation by bromine at different $\mathrm{SO}_{2}$ concentrations for two sets of experimental conditions; one is with the $\mathrm{SO}_{2}$ injected as usual through the methane burner. The other is with $\mathrm{SO}_{2}$ injected through the $\mathrm{KCl}$ impinger on the elemental side of the conditioning system. There is not a significant difference in levels of oxidation for the two conditions. This suggests that the effect of $\mathrm{SO}_{2}$ on mercury oxidation by bromine is due liquid-phase reactions in the $\mathrm{KCl}$ impinger.

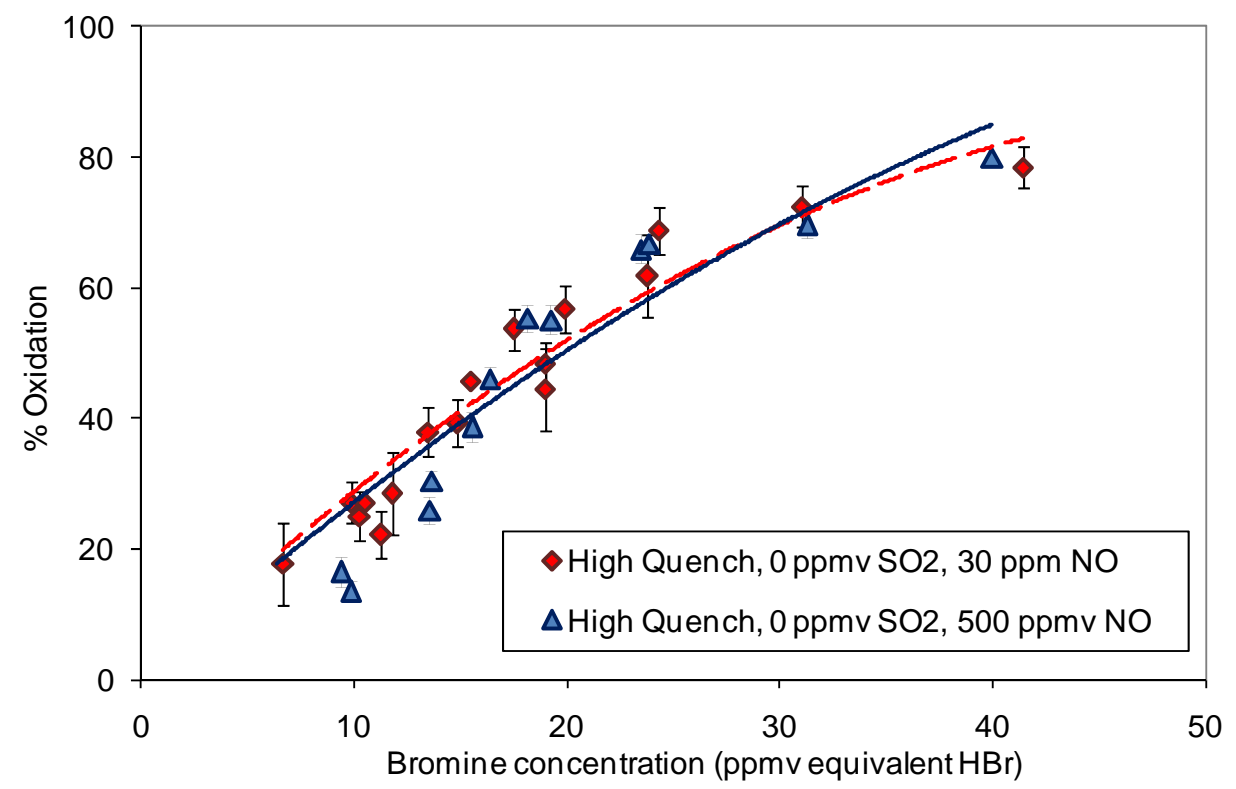

Figure 17. Effect of NO on mercury oxidation by bromine at high quench rate. 


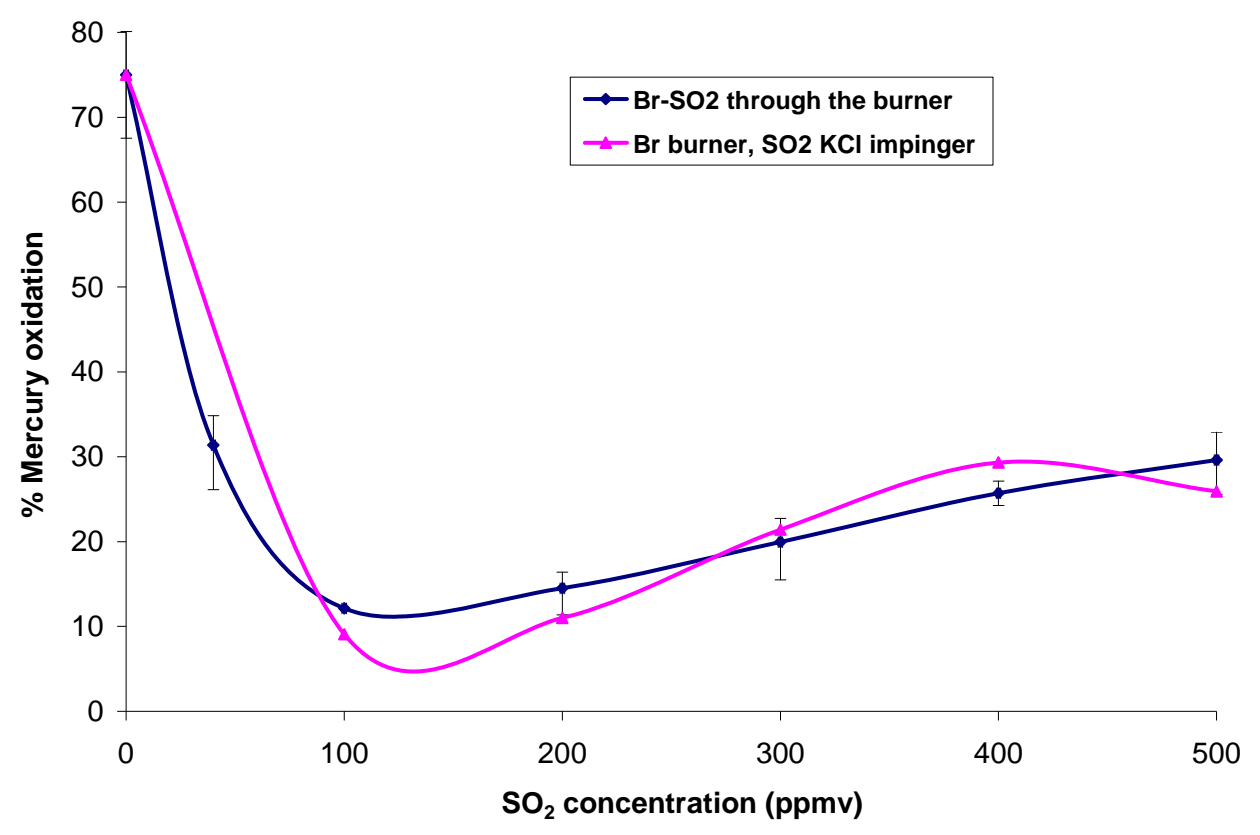

Figure 18. Effect of $\mathrm{SO}_{2}$ on mercury oxidation by $45 \mathrm{ppm}$ bromine (as $\mathrm{HBr}$ equivalent) using the high quench temperature profile. In one case the $\mathrm{SO}_{2}$ was added through the burner, in the other it was added directly to the $\mathrm{KCl}$ impinger.

Measurements of $\mathrm{SO}_{2}$ concentration were made before and after the two impinger solutions on the elemental side of the conditioning system to determine where $\mathrm{SO}_{2}$ was being consumed. The flow of $\mathrm{SO}_{2}$ to the burner was set by a mass flow controller and the measurements were done using a non-dispersive infrared gas analyzer (Model 600, California Analytical Instruments Inc.). Figure 19 shows the sampling points. The first is before the $\mathrm{KCl}$ impinger, the second is after the $\mathrm{KCl}$ impinger, and the third is after the $\mathrm{NaOH}$ impinger.

No $\mathrm{SO}_{2}$ was detected in the samples taken from the third location, indicating that the $\mathrm{NaOH}$ impinger removes all $\mathrm{SO}_{2}$ from the sample stream before it proceeds to the chiller. Figure 20 shows $\mathrm{SO}_{2}$ concentrations with and without bromine for the first (before the $\mathrm{KCl}$ impinger) and second (after the $\mathrm{KCl}$ impinger) locations. In the absence of bromine, little $\mathrm{SO}_{2}$ is removed by the $\mathrm{KCl}$ impinger. In the presence of $50 \mathrm{ppm}$ bromine (as $\mathrm{HBr}$ equivalent) an average of $25 \mathrm{ppm} \mathrm{SO}$ is removed in the $\mathrm{KCl}$ impinger for $\mathrm{SO}_{2}$ concentrations ranging from 200-400 ppm. This reduction suggests that $\mathrm{SO}_{2}$ may be reacting with $\mathrm{Br}_{2}$ in the $\mathrm{KCl}$ impinger. A known reaction between bromine and $\mathrm{SO}_{2}$ is

$$
\mathrm{SO}_{2}(\mathrm{~g})+\mathrm{Br}_{2}(\mathrm{~g})+2 \mathrm{H}_{2} \mathrm{O}(\mathrm{l})=2 \mathrm{HBr}(\mathrm{aq})+\mathrm{H}_{2} \mathrm{SO}_{4}(\mathrm{aq})
$$


According to Ishikawa et al. ${ }^{25}$, this reaction is used to produce lab-scale quantities of $\mathrm{HBr}$. Velzen et al. ${ }^{26}$ performed vapor-liquid equilibrium calculations and noted that at low concentrations of sulfuric acid in the liquid, only traces of $\mathrm{SO}_{2}$ and $\mathrm{Br}_{2}$ remained in the gas at equilibrium.

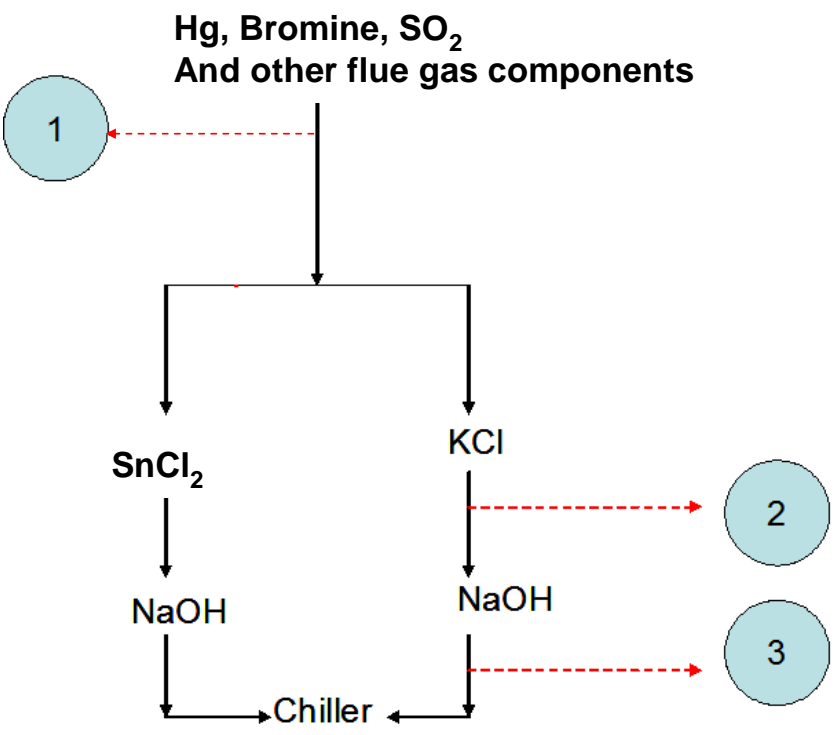

Figure 19. Sample points for $\mathrm{SO}_{2}$ measurements.

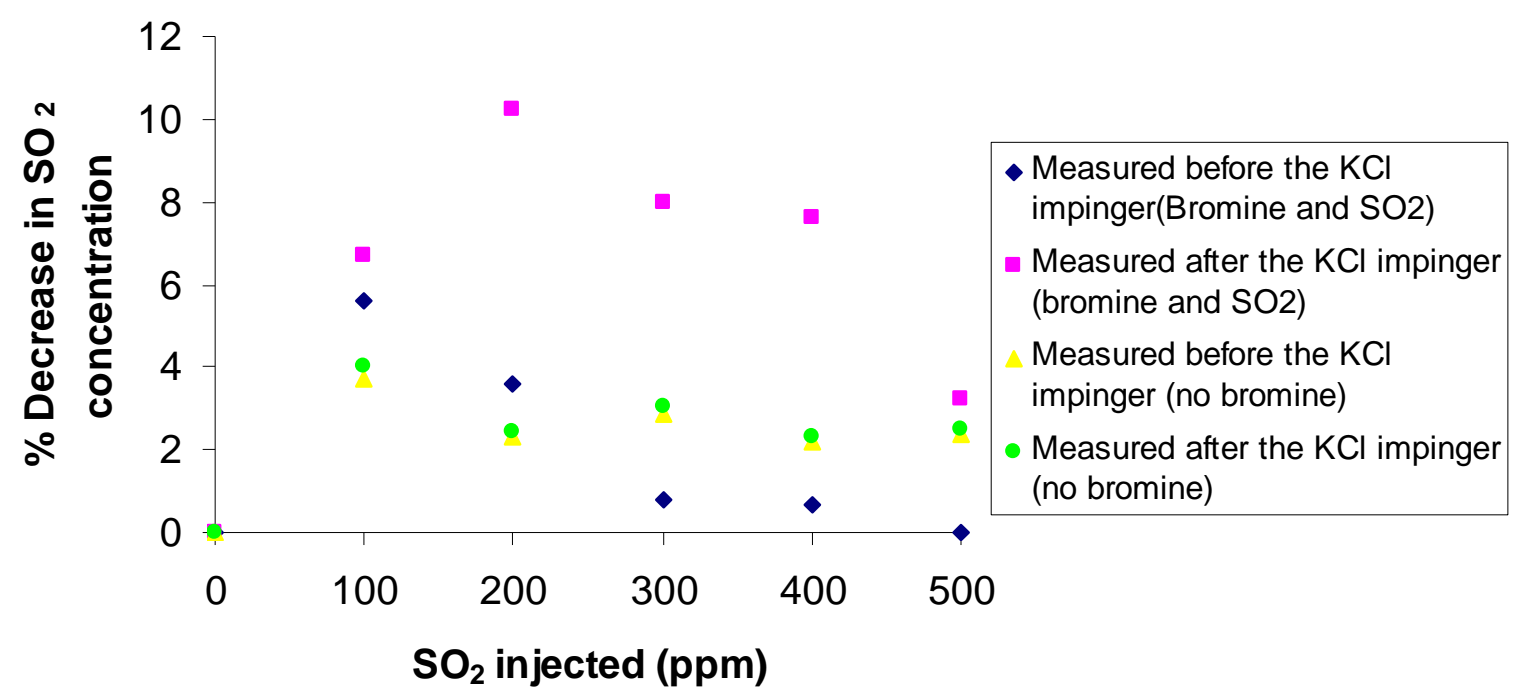

Figure 20. $\mathrm{SO}_{2}$ concentration measurements with and without $50 \mathrm{ppm}$ bromine (as $\mathrm{HBr}$ equivalent) using the high quench temperature profile. 
Figure 18 shows an apparent dramatic decline in $\mathrm{Hg}$ oxidation by bromine in the presence of $\mathrm{SO}_{2}$. In the previous section on impinger chemistry, Figures 9 and 10 show that this decline can be mitigated by the placement of a $\mathrm{NaOH}$ impinger or heated bed of $\mathrm{NaOH}$ pellets before the $\mathrm{KCl}$ impinger. It is not known why the effect of adding $\mathrm{SO}_{2}$ through the burner decreases or disappears entirely at $\mathrm{SO}_{2}$ concentrations above 200 or 300 ppm.

\section{Modeling Gas-Phase Kinetics of Mercury Oxidation by Halogens}

The laboratory data generated in this program are the first homogeneous data on halogeninduced oxidation of mercury in a combustion system. Laboratory experiments have been performed at fixed temperatures under batch conditions. ${ }^{27}$ Slipstream data taken at a coalfired power plant have been reported, ${ }^{28}$ in which $\operatorname{HBr}(\mathrm{g})$ was added to coal combustion flue gas. The presence of ash in these experiments calls into question whether the reported oxidation was truly homogeneous. Thus, the data generated in this program represent a unique opportunity to validate homogeneous kinetic models.

Several detailed, homogeneous, mercury-halogen kinetic mechanisms are available in the literature or are currently under development. Five $\mathrm{Hg}-\mathrm{Cl}$ and three $\mathrm{Hg}-\mathrm{Br}$ mechanisms were evaluated and compared to gas-phase experimental data taken at the University of Utah. The various kinetic mechanism tested are shown in Table 2 through Table 9. The kinetic parameters shown are for the modified Arrhenius rate equation, shown in Equation 1.

$$
k=A T^{n} \exp \left(-\frac{E_{a}}{R T}\right)
$$

Table 2. UConn Hg-Cl kinetic mechanism. ${ }^{29,30,31,32}$

\begin{tabular}{|l|l|l|l|l|}
\hline Reaction & & $\mathrm{A}(\mathrm{mol}-\mathrm{cm}-\mathrm{s}-\mathrm{K})$ & $\mathrm{n}$ & $\mathrm{E}_{\mathrm{a}}(\mathrm{cal} / \mathrm{mol})$ \\
\hline HG+CL+M=HGCL+M & & $9.00 \mathrm{E}+15$ & 0.5 & 0 \\
\hline HG+CL2=HGCL+CL & & $3.26 \mathrm{E}+10$ & 0 & 22800 \\
\hline HG+HOCL=HGCL+OH & & $3.43 \mathrm{E}+12$ & 0 & 12790 \\
\hline HG+HCL=HGCL+H & & $4.94 \mathrm{E}+14$ & 0 & 79300 \\
\hline HGCL+CL2=HGCL2+CL & & $2.02 \mathrm{E}+14$ & 0 & 3280 \\
\hline HGCL+HCL=HGCL2+H & & $4.94 \mathrm{E}+14$ & 0 & 21500 \\
\hline HGCL+CL+M=HGCL2+M & & $1.16 \mathrm{E}+16$ & 0.5 & 0 \\
\hline HGCL+HOCL=HGCL2+OH & $4.27 \mathrm{E}+13$ & 0 & 1000 \\
\hline
\end{tabular}


Table 3. Wilcox Hg-Cl kinetic mechanism. ${ }^{33,34}$

\begin{tabular}{|l|l|l|l|}
\hline Reaction & A (mol-cm-s-K) & $n$ & $E_{a}(\mathrm{cal} / \mathrm{mol})$ \\
\hline HGCL+M=HG+CL+M & $4.25 \mathrm{E}+13$ & 0 & 16100 \\
\hline HG+CL2=HGCL+CL & $1.34 \mathrm{E}+12$ & 0 & 42800 \\
\hline HG+HOCL=HGCL+OH & $3.09 \mathrm{E}+13$ & 0 & 36600 \\
\hline HG+HCL=HGCL+H & $2.62 \mathrm{E}+12$ & 0 & 82100 \\
\hline HGCL+CL2=HGCL2+CL & $2.47 \mathrm{E}+10$ & 0 & 0 \\
\hline HGCL+HCL=HGCL2+H & $3.11 \mathrm{E}+11$ & 0 & 30270 \\
\hline HGCL2+M=HGCL+CL+M & $2.87 \mathrm{E}+13$ & 0 & 80600 \\
\hline HGCL+HOCL=HGCL2+OH & $3.48 \mathrm{E}+10$ & 0 & 0 \\
\hline HGCL2+M=HG+CL2+M & $3.19 \mathrm{E}+11$ & 0 & 87000 \\
\hline
\end{tabular}

Table 4. Helble 2007 Hg-Cl kinetic mechanism.

\begin{tabular}{|l|l|l|l|l|}
\hline Reaction & & A (mol-cm-s-K) & $\mathrm{n}$ & $\mathrm{E}_{\mathrm{a}}(\mathrm{cal} / \mathrm{mol})$ \\
\hline HG+CL+M=HGCL+M & & $1.92 \mathrm{E}+13$ & 1 & 2130 \\
\hline HG+CL2=HGCL+CL & & $4.52 \mathrm{E}+13$ & 0 & 35994 \\
\hline HG+HOCL=HGCL+OH & $2.70 \mathrm{E}+14$ & 0 & 31801 \\
\hline HG+HCL=HGCL+H & $2.76 \mathrm{E}+15$ & 0 & 79782 \\
\hline HGCL+CL2=HGCL2+CL & $2.45 \mathrm{E}+05$ & 2.4 & -2353 \\
\hline HGCL+HCL=HGCL2+H & $2.49 \mathrm{E}+13$ & 0 & 24967 \\
\hline HGCL+CL+M=HGCL2+M & $1.66 \mathrm{E}+12$ & 1 & -1203 \\
\hline HGCL+HOCL=HGCL2+OH & $3.28 \mathrm{E}+05$ & 2.4 & 294 \\
\hline
\end{tabular}


Table 5. Bozzelli 2010 Hg-Cl kinetic mechanism.

\begin{tabular}{|l|l|l|l|}
\hline Reaction & A (mol-cm-s-K) & $n$ & $\mathrm{E}_{\mathrm{a}}(\mathrm{cal} / \mathrm{mol})$ \\
\hline HG + CL $<=>$ HGCL & $5.54 \mathrm{E}+14$ & -0.24 & 1217 \\
\hline HG + CL2 = HGCL + CL & $1.92 \mathrm{E}+16$ & -0.67 & 31617 \\
\hline HG + HOCL = HGCL + OH & $2.50 \mathrm{E}+12$ & 0 & 32000 \\
\hline HG + HCL $=$ HGCL + H & $4.94 \mathrm{E}+14$ & 0 & 79300 \\
\hline HGCL + CL2 = HGCL2 + CL & $1.39 \mathrm{E}+14$ & 0 & 1000 \\
\hline HGCL + HCL <=> HGCL2 + H & $8.50 \mathrm{E}+11$ & 0 & 23500 \\
\hline HGCL + CL <=> HGCL2 & $1.23 \mathrm{E}+18$ & -4.54 & 1142 \\
\hline HGCL + HOCL <=> HGCL2 + OH & $6.20 \mathrm{E}+11$ & 0 & 2000 \\
\hline HG + CLO = HGO + CL & $1.38 \mathrm{E}+12$ & 0 & 8320 \\
\hline HG + CL2 = HGCL2 & $2.68 \mathrm{E}+23$ & -3.57 & 13042 \\
\hline HGCL + OH <=> HGOHCL & $6.77 \mathrm{E}+25$ & -9.17 & 593 \\
\hline HGCL + OH <=> HGOH + CL & $1.07 \mathrm{E}+23$ & -4.17 & 2017 \\
\hline HGOHCL <=> HGOH + CL & $3.81 \mathrm{E}+30$ & -5.62 & 66104 \\
\hline HGOH + CL <=> HGO + HCL & $1.00 \mathrm{E}+13$ & 0 & 10000 \\
\hline $\begin{array}{l}\text { HGOHCL + CL }<=>\text { HGCLO + } \\
\text { HCL }\end{array}$ & $1.00 \mathrm{E}+13$ & 0 & 12000 \\
\hline $\begin{array}{l}\text { HGOHOH + CL }<=>\text { HGOHO + } \\
\text { HCL }\end{array}$ & $1.00 \mathrm{E}+13$ & 0 & 12000 \\
\hline HGOHCL + OH = HGCLO + H2O & $2.45 \mathrm{E}+12$ & 0 & 4100 \\
\hline HGO + HCL = HGCL + OH & $9.63 \mathrm{E}+04$ & 0 & 8920 \\
\hline HGO + HOCL = HGCL + HO2 & $4.11 \mathrm{E}+13$ & 0 & 60470 \\
\hline
\end{tabular}

Table 6. Xu 2003 Hg-Cl kinetic mechanism. ${ }^{35}$

\begin{tabular}{|l|l|l|l|}
\hline Reaction & A (mol-cm-s-K) & $n$ & $\mathrm{E}_{\mathrm{a}}(\mathrm{cal} / \mathrm{mol})$ \\
\hline HG + CL + M = HGCL + M & $2.40 \mathrm{E}+08$ & 1.4 & $-1.44 \mathrm{E}+04$ \\
\hline HG + CL2 = HGCL + CL & $1.39 \mathrm{E}+14$ & 0 & $3.40 \mathrm{E}+04$ \\
\hline HG + HOCL = HGCL + OH & $4.27 \mathrm{E}+13$ & 0 & $1.90 \mathrm{E}+04$ \\
\hline HG + HCL = HGCL + H & $4.94 \mathrm{E}+14$ & 0 & $7.93 \mathrm{E}+04$ \\
\hline HGCL + CL2 = HGCL2 + CL & $1.39 \mathrm{E}+14$ & 0 & $1.00 \mathrm{E}+03$ \\
\hline HGCL + HCL = HGCL2 + H & $4.94 \mathrm{E}+14$ & 0 & $2.15 \mathrm{E}+04$ \\
\hline HGCL + CL + M = HGCL2 + M & $2.19 \mathrm{E}+18$ & 0 & $3.10 \mathrm{E}+03$ \\
\hline HGCL + HOCL = HGCL2 + OH & $4.27 \mathrm{E}+13$ & 0 & $1.00 \mathrm{E}+03$ \\
\hline HG + CLO = HGO + CL & $1.38 \mathrm{E}+12$ & 0 & 8320 \\
\hline HGO + HCL = HGCL + OH & $9.63 \mathrm{E}+04$ & 0 & 8920 \\
\hline HGO + HOCL = HGCL + HO2 & $4.11 \mathrm{E}+13$ & 0 & 60470 \\
\hline HG + CLO2 = HGO + CLO & $1.87 \mathrm{E}+07$ & 0 & 51270 \\
\hline
\end{tabular}


Table 7. Niksa Hg-Br kinetic mechanism. ${ }^{36}$

\begin{tabular}{|l|l|l|l|l|}
\hline Reaction & & A (mol-cm-s-K) & $\mathrm{n}$ & $\mathrm{E}_{\mathrm{a}}(\mathrm{cal} / \mathrm{mol})$ \\
\hline HG + BR + M = HGBR + M & & $6.94 \mathrm{E}+14$ & 0.5 & 0 \\
\hline HG + BR2 = HGBR + BR & & $1.15 \mathrm{E}+14$ & 0 & 31800 \\
\hline HG + HBR = HGBR + H & & $3.78 \mathrm{E}+14$ & 0 & 75700 \\
\hline HG + BROH = HGBR + OH & & $3.52 \mathrm{E}+13$ & 0 & 36900 \\
\hline HGBR + BR2 = HGBR2 + BR & $1.11 \mathrm{E}+14$ & 0 & 500 \\
\hline HGBR + BR + M = HGBR2 + M & $8.83 \mathrm{E}+14$ & 0.5 & 0 \\
\hline HGBR + HBR = HGBR2 + H & $1.16 \mathrm{E}+07$ & 2.5 & 28100 \\
\hline HGBR + BROH = HGBR2 + OH & & $3.47 \mathrm{E}+13$ & 0 & 5500 \\
\hline HGBR + CL2 = HGBRCL + CL & & $1.39 \mathrm{E}+14$ & 0 & 100 \\
\hline HGBR + HOCL = HGBRCL + OH & & $4.27 \mathrm{E}+13$ & 0 & 3300 \\
\hline HG + BRCL = HGBR + CL & $1.39 \mathrm{E}+14$ & 0 & 32100 \\
\hline HGBR + CL + M = HGBRCL + M & $1.16 \mathrm{E}+15$ & 0.5 & 0 \\
\hline HGBR + HCL = HGBRCL + H & $4.64 \mathrm{E}+03$ & 2.5 & 18200 \\
\hline
\end{tabular}


Table 8. Bozzelli 2006 Hg-Br kinetic mechanism.

\begin{tabular}{|c|c|c|c|}
\hline Reaction & $\begin{array}{l}\text { A (mol-cm-s- } \\
\text { K) }\end{array}$ & $\mathrm{n}$ & $\mathrm{E}_{\mathrm{a}}(\mathrm{cal} / \mathrm{mol})$ \\
\hline $\mathrm{HG}+\mathrm{BR}+\mathrm{M}<=>\mathrm{HGBR}+\mathrm{M}$ & $2.93 \mathrm{E}+15$ & 0 & 0 \\
\hline $\mathrm{BR}+\mathrm{HGBR}=\mathrm{BR} 2+\mathrm{HG}$ & $1.39 \mathrm{E}+13$ & 0 & 2100 \\
\hline $\mathrm{H}+\mathrm{HGBR}<=>\mathrm{HBR}+\mathrm{HG}$ & $2.70 \mathrm{E}+13$ & 0 & 2300 \\
\hline $\mathrm{OH}+\mathrm{HGBR}<=>\mathrm{BROH}+\mathrm{HG}$ & $3.27 \mathrm{E}+12$ & 0 & 1000 \\
\hline HGBR + BR2 $<=>$ HGBR2 + BR & $7.39 \mathrm{E}+12$ & 0 & 1000 \\
\hline $\mathrm{HGBR}+\mathrm{BR}+\mathrm{M}<=>\mathrm{HGBR} 2+\mathrm{M}$ & $4.60 \mathrm{E}+16$ & 0.5 & 0 \\
\hline HGBR2 $+\mathrm{H}<=>$ HGBR + HBR & $4.64 \mathrm{E}+03$ & 2.5 & 1910 \\
\hline $\mathrm{HGBR}+\mathrm{BROH}<=>\mathrm{HGBR} 2+\mathrm{OH}$ & $2.27 \mathrm{E}+12$ & 0 & 1700 \\
\hline HGBR + CL2 = HGBRCL + CL & $6.70 \mathrm{E}+12$ & 0 & 1250 \\
\hline $\mathrm{HGBR}+\mathrm{HOCL}=\mathrm{HGBRCL}+\mathrm{OH}$ & $1.70 \mathrm{E}+12$ & 0 & 1150 \\
\hline $\mathrm{BRO}+\mathrm{HGBR}=\mathrm{HGBR} 2+\mathrm{O}$ & $2.25 \mathrm{E}+12$ & 0 & 4550 \\
\hline $\mathrm{HGBR}+\mathrm{O}=\mathrm{BRO}+\mathrm{HG}$ & $3.35 \mathrm{E}+13$ & 0 & 1300 \\
\hline $\mathrm{HGCL}+\mathrm{BR2}=\mathrm{HGBRCL}+\mathrm{BR}$ & $8.20 \mathrm{E}+11$ & 0 & 1050 \\
\hline $\mathrm{HGOH}+\mathrm{BR}<=>\mathrm{HGBROH}$ & $1.57 \mathrm{E}+30$ & -7.28 & 1903 \\
\hline $\mathrm{HGOH}+\mathrm{BR}<=>\mathrm{HGBR}+\mathrm{OH}$ & $6.67 \mathrm{E}+13$ & -0.36 & 218 \\
\hline $\mathrm{HGBR}+\mathrm{OH}<=>\mathrm{HGBROH}$ & $2.19 \mathrm{E}+29$ & -5.77 & 2976 \\
\hline $\mathrm{HGO}+\mathrm{BR}<=>\mathrm{HGBRO}$ & $8.29 \mathrm{E}+24$ & -4.75 & 1735 \\
\hline $\mathrm{HGBROH}+\mathrm{OH}=\mathrm{HGBRO}+\mathrm{H} 2 \mathrm{O}$ & $2.45 \mathrm{E}+12$ & 0 & 850 \\
\hline $\mathrm{HGBRO}+\mathrm{HO} 2=\mathrm{HGBROH}+\mathrm{O} 2$ & $5.50 \mathrm{E}+11$ & 0 & 0 \\
\hline HGCL + BRNO = HGBRCL + NO & $8.20 \mathrm{E}+11$ & 0 & 1050 \\
\hline $\mathrm{HGBR}+\mathrm{BRNO}=\mathrm{HGBR} 2+\mathrm{NO}$ & $6.70 \mathrm{E}+11$ & 0 & 1050 \\
\hline $\mathrm{HGOH}+\mathrm{BRNO}=\mathrm{HGBROH}+\mathrm{NO}$ & $1.20 \mathrm{E}+12$ & 0 & 1050 \\
\hline HGBR + NOCL $=$ HGBRCL + NO & $7.50 \mathrm{E}+11$ & 0 & 1050 \\
\hline HGCL + BRNO2 = HGBRCL + NO2 & $8.20 \mathrm{E}+11$ & 0 & 1050 \\
\hline $\mathrm{HGBR}+\mathrm{BRNO} 2=\mathrm{HGBR} 2+\mathrm{NO} 2$ & $6.70 \mathrm{E}+11$ & 0 & 1050 \\
\hline $\mathrm{HGOH}+\mathrm{BRNO} 2=\mathrm{HGBROH}+\mathrm{NO} 2$ & $1.20 \mathrm{E}+12$ & 0 & 1050 \\
\hline HGBR + CLNO2 = HGBRCL + NO2 & $7.50 \mathrm{E}+11$ & 0 & 1050 \\
\hline $\mathrm{HGCL}+\mathrm{BRO}=\mathrm{HGBRCL}+\mathrm{O}$ & $3.20 \mathrm{E}+12$ & 0 & 1350 \\
\hline $\mathrm{HGOH}+\mathrm{BRO}=\mathrm{HGBROH}+\mathrm{O}$ & $2.20 \mathrm{E}+12$ & 0 & 1550 \\
\hline $\mathrm{HGBR}+\mathrm{CLO}=\mathrm{HGBRCL}+\mathrm{O}$ & $2.90 \mathrm{E}+12$ & 0 & 1050 \\
\hline HGCL + BROH $=$ HGBRCL + OH & $8.70 \mathrm{E}+11$ & 0 & 1350 \\
\hline $\mathrm{HGOH}+\mathrm{BROH}=\mathrm{HGBROH}+\mathrm{OH}$ & $1.80 \mathrm{E}+12$ & 0 & 1650 \\
\hline
\end{tabular}


Table 9. Bozzelli 2010 Hg-Br kinetic mechanism.

\begin{tabular}{|l|l|l|l|}
\hline Reaction & A (mol-cm-s-K) & $n$ & $\mathrm{E}_{\mathrm{a}}(\mathrm{cal} / \mathrm{mol})$ \\
\hline HG + BR $<=>$ HGBR & $5.20 \mathrm{E}+18$ & -2.86 & 461 \\
\hline HG + BR2 $=$ HGBR + BR & $9.94 \mathrm{E}+20$ & -2.42 & 28933 \\
\hline HGBR + H $<=>$ HG + HBR & $2.70 \mathrm{E}+13$ & 0 & 2300 \\
\hline HGBR + OH $<=>$ HG + HOBR & $3.27 \mathrm{E}+12$ & 0 & 1000 \\
\hline HGBR + BR2 <=> HGBR2 + BR & $7.39 \mathrm{E}+12$ & 0 & 1000 \\
\hline HGBR + BR $<=>$ HGBR2 & $3.80 \mathrm{E}+24$ & -4.17 & 1974 \\
\hline HGBR2 + H $<=>$ HGBR + HBR & $4.64 \mathrm{E}+03$ & 2.5 & 1910 \\
\hline HGBR + HOBR $<=>$ HGBR2 + OH & $2.27 \mathrm{E}+12$ & 0 & 1700 \\
\hline HGBR + CL2 $=$ HGBRCL + CL & $6.70 \mathrm{E}+12$ & 0 & 1250 \\
\hline HGBR + BRO = HGBR2 + O & $2.25 \mathrm{E}+12$ & 0 & 1150 \\
\hline HGBR + O = BRO + HG & $3.35 \mathrm{E}+13$ & 0 & 1300 \\
\hline HGCL + BR2 = HGBRCL + BR & $8.20 \mathrm{E}+11$ & 0 & 1050 \\
\hline HGOH + BR $<=>$ HGBROH & $1.57 \mathrm{E}+30$ & -7.28 & 1903 \\
\hline HGOH + BR $<=>$ HGBR + OH & $6.67 \mathrm{E}+13$ & -0.36 & 218 \\
\hline HGBR + OH $<=>$ HGBROH & $2.19 \mathrm{E}+29$ & -5.77 & 2976 \\
\hline HGO + BR $<=>$ HGBRO & $8.29 \mathrm{E}+24$ & -4.75 & 1735 \\
\hline HGBROH + OH $=$ HGBRO + H2O & $2.45 \mathrm{E}+12$ & 0 & 850 \\
\hline HGBRO + HO2 $=$ HGBROH + O2 & $5.50 \mathrm{E}+11$ & 0 & 0 \\
\hline HG + BR2 $=$ HGBR2 & $1.19 \mathrm{E}+11$ & -0.01 & 4736 \\
\hline
\end{tabular}

The various mercury-halogen kinetic sets were combined with the REI halogen kinetic set and submechanisms for $\mathrm{NO}_{\mathrm{x}}, \mathrm{SO}_{\mathrm{x}}$, and hydrocarbon chemistry in order to accurately model the conditions of the University of Utah experiments. The detailed halogen kinetic set used in the REI modeling is a combination of reactions from several sources. The chlorine mechanism consists of $\mathrm{Cl}$ reactions from Roesler ${ }^{37}$, additional NO-Cl reactions from Niksa and Bozzelli, and $\mathrm{C}_{\mathrm{x}} \mathrm{H}_{\mathrm{y}}-\mathrm{Cl}$ reactions from Bozzelli. The bromine kinetic set contains reactions from the NIST Halon mechanism ${ }^{38}$ and several additional reactions with $\mathrm{NO}_{\mathrm{x}}, \mathrm{Cl}$, and $\mathrm{OH}$ from Bozzelli. Two experimental data sets are presented: high quench time-temperature profile (HQ, $440 \mathrm{~K} / \mathrm{s}$ ) and low quench time-temperature profile (LQ, $210 \mathrm{~K} / \mathrm{s}$ ). Both time-temperature histories were modeled with each $\mathrm{Hg}-\mathrm{Cl}$ or $\mathrm{Hg}-\mathrm{Br}$ kinetic set.

\section{Mercury Oxidation by Chlorine}

The various $\mathrm{Hg}-\mathrm{Cl}$ mechanisms tested are compared to the experimental data in Figures 21 and 22. The UConn, Wilcox, and Helble kinetics under-predict oxidation for both the HQ and LQ data sets. The Bozzelli Hg-Cl kinetics over-predict mercury oxidation for both the HQ and LQ data sets. The Xu kinetics over-predict oxidation for the HQ data set 
and under-predict oxidation for the LQ data set. Based on these results, the Xu kinetics provide the most accurate prediction of the $\mathrm{Hg}-\mathrm{Cl}$ oxidation data.

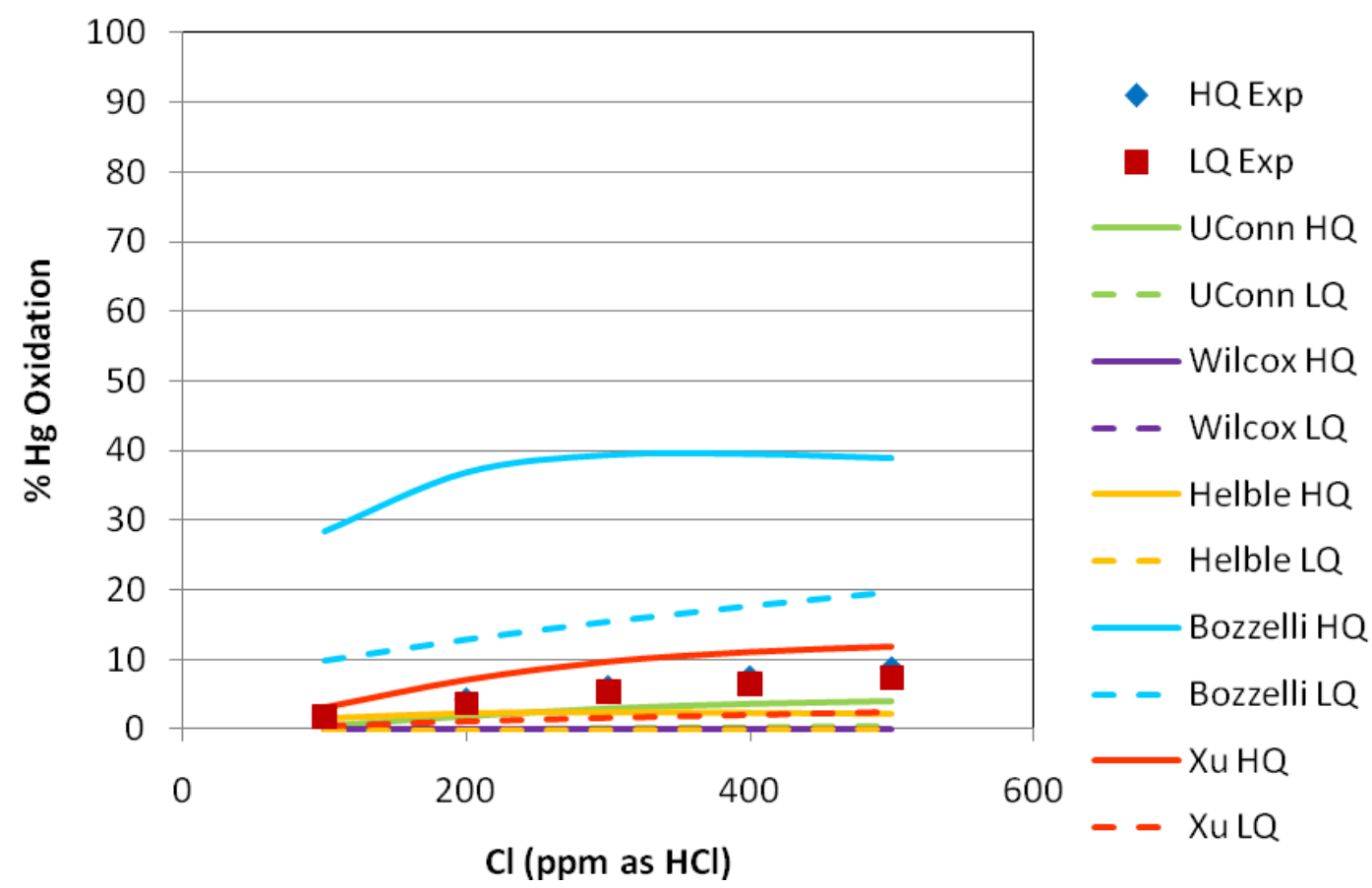

Figure 21. Comparison of various Hg-Cl kinetic mechanisms and experimental data. 


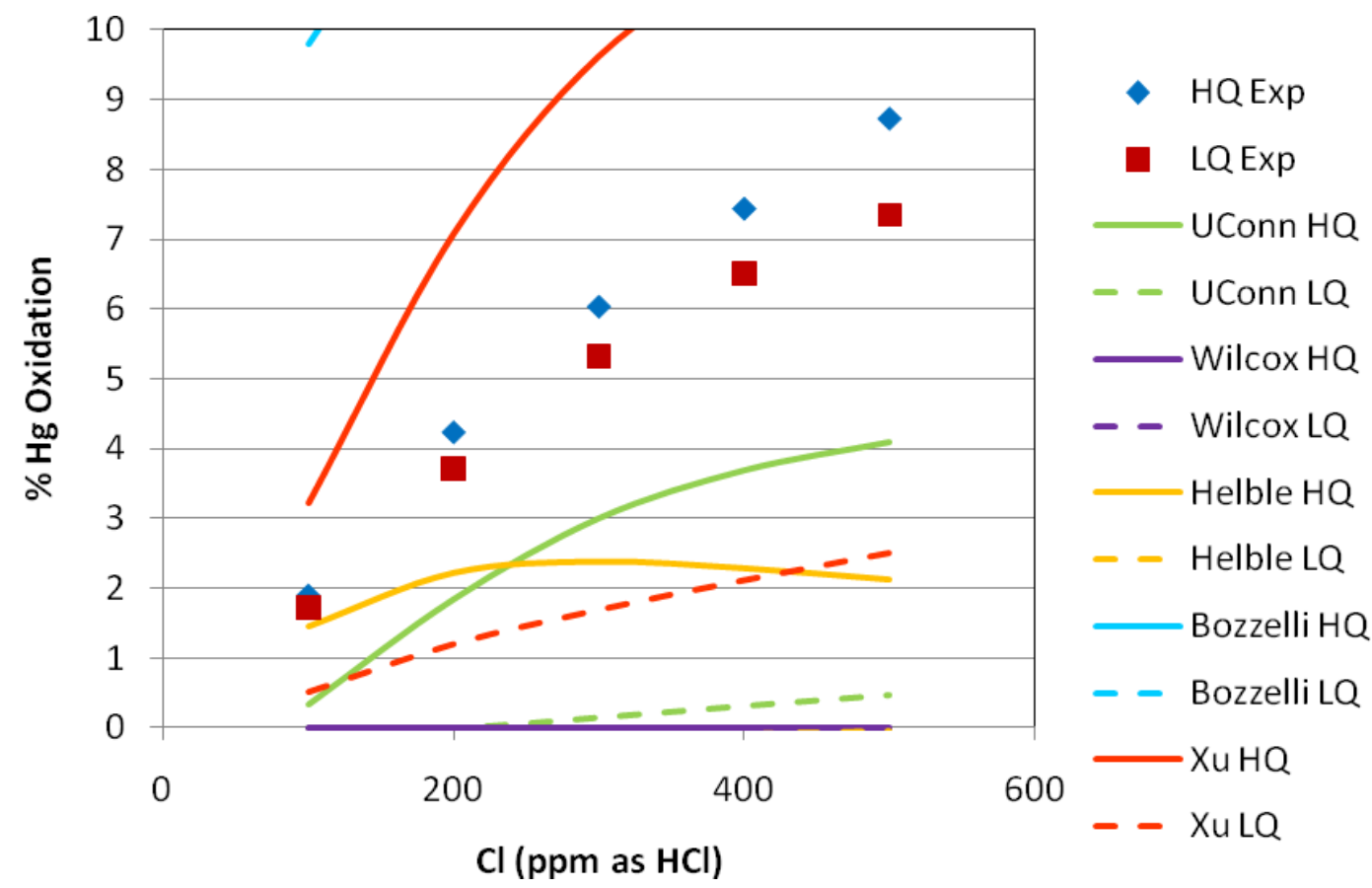

Figure 22. Zoomed in view of the comparison of various $\mathrm{Hg}-\mathrm{Cl}$ kinetic mechanisms and experimental data.

The Hg-Cl mechanism used by Xu contains kinetics for eight reactions from Widmer et al. ${ }^{31}$ and four additional reactions with novel kinetics. In an effort to better understand the importance of individual reactions in the mechanism, a sensitivity analysis was performed in which one reaction at a time was removed. The resulting mercury oxidation using the HQ temperature profile and $500 \mathrm{ppmv} \mathrm{Cl}$ was then compared to the full mechanism. The results from this analysis are shown in Table 10. Three reactions were found to have a significant impact on mercury oxidation. Two reactions $\left(\mathrm{Hg}+\mathrm{Cl}+\mathrm{M}=\mathrm{HgCl}+\mathrm{M}\right.$ and $\left.\mathrm{HgCl}+\mathrm{CL}_{2}=\mathrm{HgCl}_{2}+\mathrm{Cl}\right)$ promoted mercury oxidation (oxidation decreased when either of these two reactions were removed) while one reaction $\left(\mathrm{HgCl}+\mathrm{HCl}=\mathrm{HgCl}_{2}+\mathrm{H}\right)$ inhibited oxidation (oxidation increased when this reaction was removed). The $\mathrm{Xu} \mathrm{Hg-Cl} \mathrm{mechanism} \mathrm{shows} \mathrm{a} \mathrm{two-step} \mathrm{reaction} \mathrm{process} \mathrm{that} \mathrm{must} \mathrm{occur}$ for mercury oxidation by chlorine.

Table 10. Results of reaction sensitivity analysis on the $\mathrm{Xu} \mathrm{Hg-Cl}$ reaction set.

\begin{tabular}{|l|l|}
\hline Reaction removed & $\begin{array}{l}\text { HQ 500 Cl } \\
\% \text { Hg Oxidation }\end{array}$ \\
\hline None & 11.75 \\
\hline HG + CL + M = HGCL + M & -0.48 \\
\hline HG + CL2 = HGCL + CL & 11.76 \\
\hline HG + HOCL = HGCL + OH & 12.27 \\
\hline
\end{tabular}




\begin{tabular}{|l|l|}
\hline HG + HCL $=$ HGCL + H & 11.75 \\
\hline HGCL + CL2 $=$ HGCL2 + CL & -0.33 \\
\hline HGCL + HCL = HGCL2 + H & 20.52 \\
\hline HGCL + CL + M = HGCL2 + M & 11.68 \\
\hline HGCL + HOCL = HGCL2 + OH & 11.75 \\
\hline HG + CLO = HGO + CL & 11.6 \\
\hline HGO + HCL = HGCL + OH & 11.72 \\
\hline HGO + HOCL = HGCL + HO2 & 11.75 \\
\hline HG + CLO2 = HGO + CLO & 11.75 \\
\hline HG + O3 = HGO + O2 & 11.75 \\
\hline HG + N2O = HGO + N2 & 11.75 \\
\hline
\end{tabular}

The same sensitivity analysis was preformed on the Bozzelli $2010 \mathrm{Hg}-\mathrm{Cl}$ kinetic set and the results are shown in Table 11. Three reactions were found to significantly affect mercury oxidation. Two of these reactions $\left(\mathrm{Hg}+\mathrm{Cl}=\mathrm{HgCl}\right.$ and $\left.\mathrm{HgCl}+\mathrm{Cl}_{2}=\mathrm{HgCl}_{2}+\mathrm{Cl}\right)$ were also found to be important in the $\mathrm{Xu}$ kinetic set while the third reaction $\left(\mathrm{Hg}+\mathrm{Cl}_{2}=\mathrm{HgCl}_{2}\right)$ was different. All three reactions promoted mercury oxidation. The first two reactions accounted for more oxidation than the third, direct oxidation reaction.

Table 11. Results of reaction sensitivity analysis on the Bozzelli $2010 \mathrm{Hg}-\mathrm{Cl}$ reaction set.

\begin{tabular}{|l|l|}
\hline Reaction removed & $\begin{array}{l}\text { HQ } 500 \mathrm{Cl} \\
\% \mathrm{Hg} \text { Oxidation }\end{array}$ \\
\hline None & 38.88 \\
\hline HG + CL $<=>$ HGCL & 17.04 \\
\hline HG + HCL = HGCL + H & 38.88 \\
\hline HGCL + CL2 = HGCL2 + CL & 17.06 \\
\hline HG + CLO = HGO + CL & 38.86 \\
\hline HGCL + HCL <=> HGCL2 + H & 38.96 \\
\hline HG + CL2 = HGCL2 & 26.03 \\
\hline HG + CL2 = HGCL + CL & 38.89 \\
\hline HGCL + CL <=> HGCL2 & 38.88 \\
\hline HGCL + OH <=> HGCLOH & 38.89 \\
\hline HGCL + OH <=> HGOH + CL & 38.88 \\
\hline HGCLOH $<=>$ HGOH + CL & 38.88 \\
\hline HGOH + CL <=> HGO + HCL & 38.88 \\
\hline HGCLOH + CL <=> HGCLO + HCL & 38.88 \\
\hline HGOHOH + CL <=> HGOHO + HCL & 38.88 \\
\hline HGCLOH + OH = HGCLO + H2O & 38.88 \\
\hline
\end{tabular}




\begin{tabular}{|l|l|}
\hline HGCL + HOCL $<=>$ HGCL2 + OH & 38.88 \\
\hline HG + HOCL $=$ HGCL + OH & 38.88 \\
\hline HGO + HCL $=$ HGCL + OH & 38.85 \\
\hline HGO + HOCL $=$ HGCL + HO2 & 38.88 \\
\hline
\end{tabular}

In an effort to improve the agreement between the experimental data and the Bozzelli 2010 reaction kinetics, several modifications were made to that $2010 \mathrm{Hg}-\mathrm{Cl}$ mechanism. Results from these modifications are shown in Figure 23. Because the Bozzelli 2010 kinetics over-predicted mercury oxidation, the first modification made was to remove the $\mathrm{Hg}+\mathrm{Cl}_{2}=\mathrm{HgCl}_{2}$ reaction pathway. This reaction was not included in any other $\mathrm{Hg}-\mathrm{Cl}$ kinetic mechanism and caused significant $\mathrm{Hg}$ oxidation. This modification lowered the predicted oxidation but the HQ experimental data were still significantly over-predicted. The second modification was to replace the kinetic parameters of Bozzelli 2010 for the reaction $\mathrm{HgCl}+\mathrm{HCl}=\mathrm{HgCl}_{2}+\mathrm{H}$ with the kinetic parameters of $\mathrm{Xu}$. This reaction in Xu's mechanism was found to inhibit oxidation, which would further decrease the oxidation predicted by Bozzelli. This second modification did further decrease oxidation, but not to the levels predicted by $\mathrm{Xu}$. The third modification was to replace the first reaction (and the associated kinetic parameters) in the Bozzelli mechanism $(\mathrm{Hg}+\mathrm{Cl}=\mathrm{HgCl})$ with the corresponding reaction and kinetic parameters in the Xu mechanism $(\mathrm{Hg}+\mathrm{Cl}+\mathrm{M}=\mathrm{HgCl}+\mathrm{M})$. This last modification brought the oxidation levels predicted by the Bozzelli $2010 \mathrm{Hg}$-Cl mechanism very close to those predicted by Xu's mechanism. The modeling results straddle either side of the HQ and LQ experimental data, but the predictions are reasonable considering the extremely low levels of oxidation measured. 


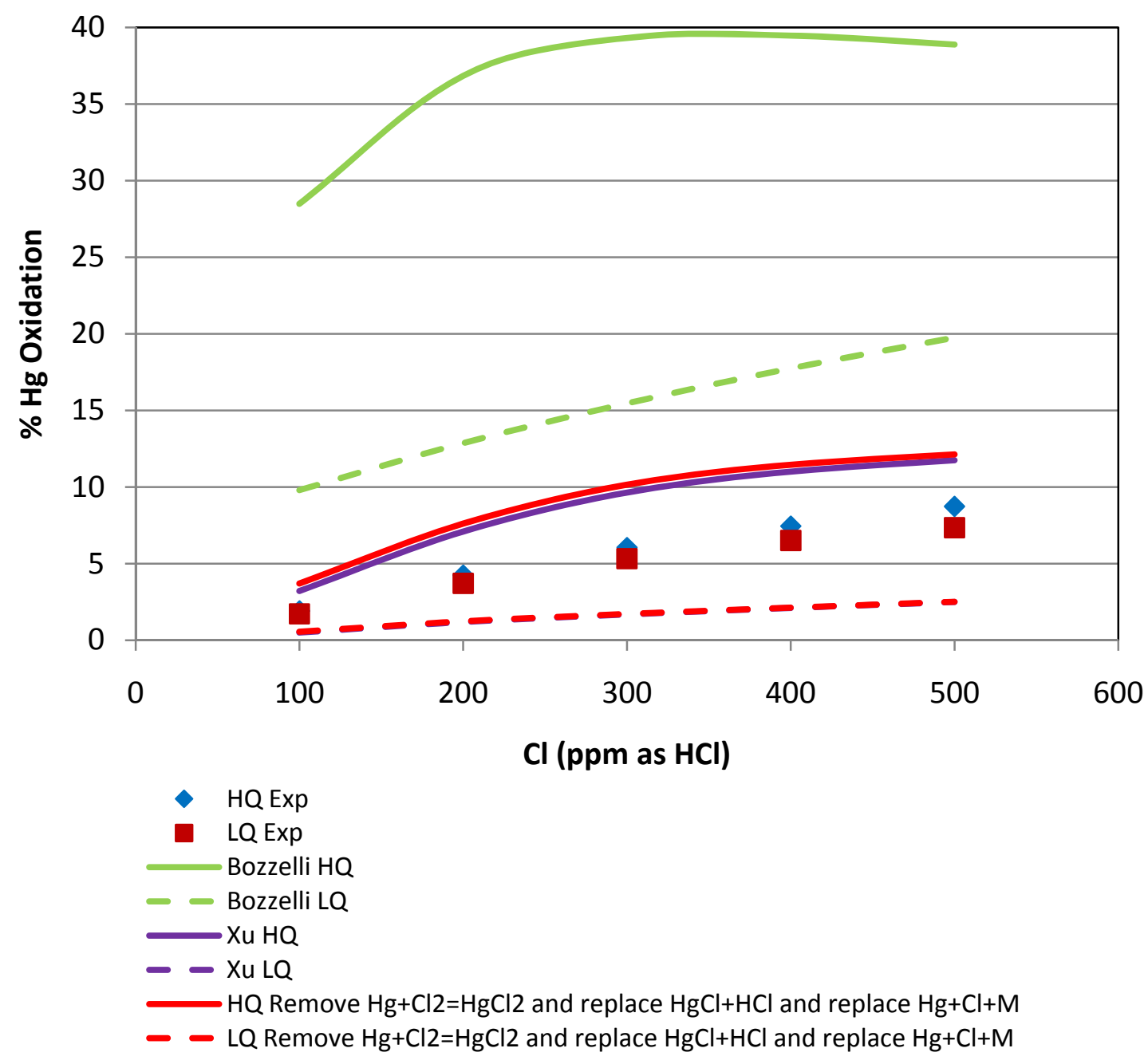

Figure 23. Results from modifications of Bozzelli $2010 \mathrm{Hg}-\mathrm{Cl}$ mechanism.

\section{Mercury Oxidation by Bromine}

Three Hg-Br mechanisms were compared to gas-phase experimental data taken at the University of Utah. The comparisons are shown in Figure 24. The Bozzelli 2006 and Niksa mechanisms drastically under-predict oxidation. The Bozzelli 2010 mechanism models the experimental data fairly well, but the effect of quench rate is not accurately predicted. While the experimental data show that the LQ time-temperature profile yields more mercury oxidation, the Bozzelli 2010 mechanism predicts that the HQ profile yields more oxidation. 


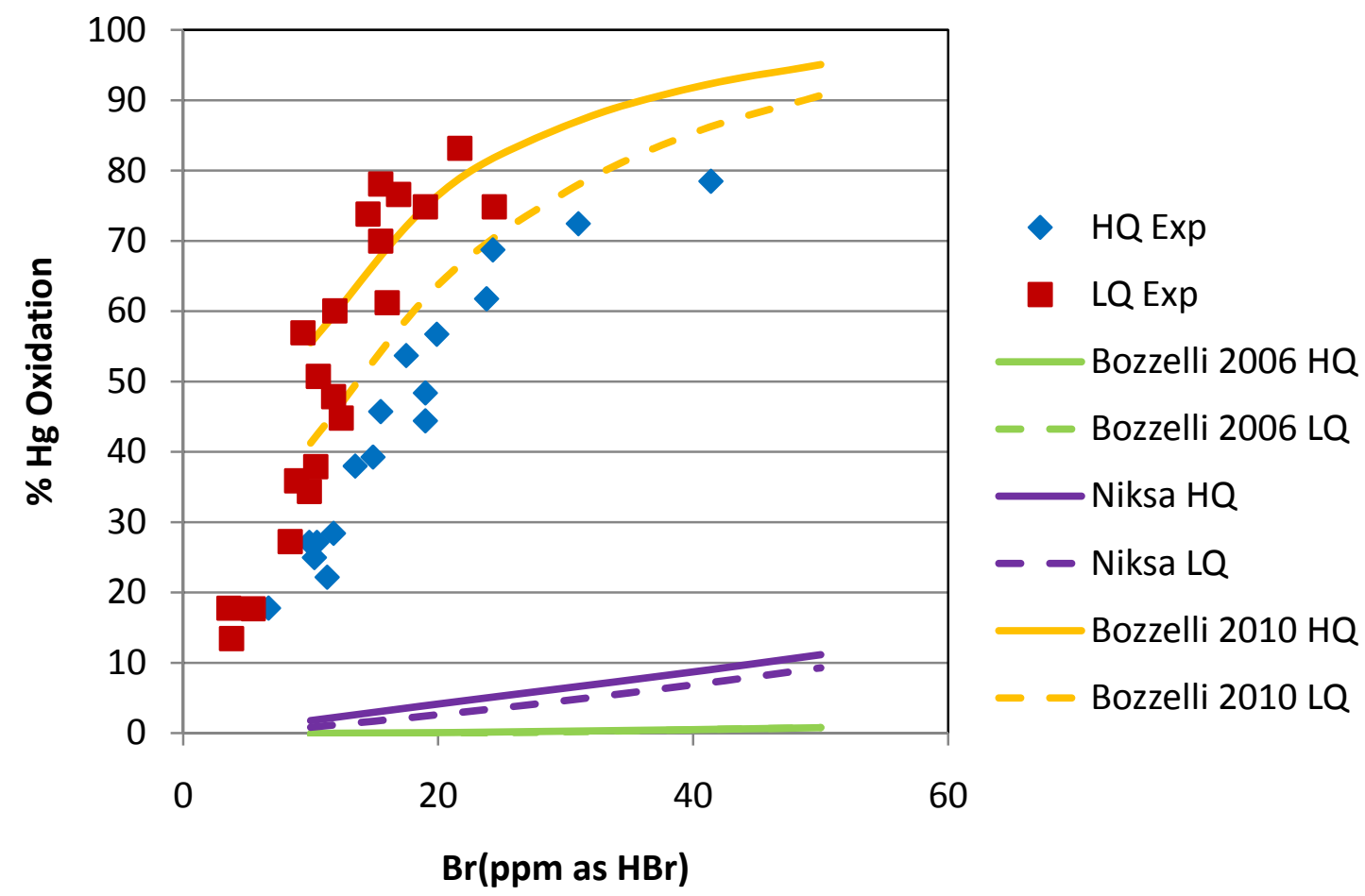

Figure 24. Comparison of various $\mathrm{Hg}-\mathrm{Br}$ kinetic mechanisms and experimental data.

A reaction sensitivity analysis was performed on the Bozzelli 2010 mechanism and the results are shown in Table 12. One reaction at a time was removed from the mechanism and the resulting mercury oxidation using the $\mathrm{HQ}$ temperature profile and $50 \mathrm{ppmv} \mathrm{Br}$ was then compared to the full mechanism. One reaction in the Bozzelli $2010 \mathrm{Hg}-\mathrm{Br}$ mechanism was found to account for nearly all mercury oxidation $\left(\mathrm{Hg}+\mathrm{Br}_{2}=\mathrm{HgBr}_{2}\right)$. While work is still need to account for the effect of quench rate, the Bozzelli $2010 \mathrm{Hg}-\mathrm{Br}$ mechanism is a significant improvement over past $\mathrm{Hg}-\mathrm{Br}$ mechanism in modeling gasphase oxidation experimental data. 
Table 12. Results of reaction sensitivity analysis on the Bozzelli $2010 \mathrm{Hg}-\mathrm{Br}$ reaction set.

\begin{tabular}{|c|c|}
\hline Reaction removed & $\begin{array}{l}\text { HQ } 50 \mathrm{Br} \\
\% \text { Hg Oxidation } \\
\end{array}$ \\
\hline None & 95.07 \\
\hline $\mathrm{HG}+\mathrm{BR}<=>\mathrm{HGBR}$ & 95.04 \\
\hline $\mathrm{HGBR}+\mathrm{H}<=>\mathrm{HG}+\mathrm{HBR}$ & 95.07 \\
\hline $\mathrm{HGBR}+\mathrm{OH}<=>\mathrm{HG}+\mathrm{BROH}$ & 95.07 \\
\hline HGBR + BR2 $<=>$ HGBR2 + BR & 95.04 \\
\hline HGBR2 $+\mathrm{H}<=>$ HGBR + HBR & 95.07 \\
\hline $\begin{array}{l}\mathrm{HGBR}+\mathrm{BROH}<=>\mathrm{HGBR} 2+ \\
\mathrm{OH}\end{array}$ & 95.07 \\
\hline $\mathrm{HGBR}+\mathrm{BRO}=\mathrm{HGBR} 2+\mathrm{O}$ & 95.07 \\
\hline $\mathrm{HGBR}+\mathrm{O}=\mathrm{BRO}+\mathrm{HG}$ & 95.07 \\
\hline $\mathrm{HG}+\mathrm{BR} 2=\mathrm{HGBR} 2$ & -0.01 \\
\hline HGBR + BR $<=>$ HGBR2 & 95.06 \\
\hline $\mathrm{HG}+\mathrm{BR} 2=\mathrm{HGBR}+\mathrm{BR}$ & 95.07 \\
\hline $\mathrm{HGOH}+\mathrm{BR}<=>\mathrm{HGBROH}$ & 95.07 \\
\hline $\mathrm{HGOH}+\mathrm{BR}<=>\mathrm{HGBR}+\mathrm{OH}$ & 95.07 \\
\hline $\mathrm{HGBR}+\mathrm{OH}<=>$ HGBROH & 95.07 \\
\hline $\mathrm{HGO}+\mathrm{BR}<=>\mathrm{HGBRO}$ & 95.07 \\
\hline $\mathrm{HGBROH}+\mathrm{OH}=\mathrm{HGBRO}+\mathrm{H} 2 \mathrm{O}$ & 95.07 \\
\hline $\mathrm{HGBRO}+\mathrm{HO} 2=\mathrm{HGBROH}+\mathrm{O} 2$ & 95.07 \\
\hline
\end{tabular}

Most of the Hg oxidation in the Bozzelli 2010 mechanism is the result of the direct reaction between $\mathrm{Hg}^{0}$ and $\mathrm{Br}_{2}$ to form $\mathrm{HgBr}_{2}$. In combustion systems, thermodynamic and kinetic calculations show that $\mathrm{Br}, \mathrm{HBr}$, and $\mathrm{Br}_{2}$ are all present at significant concentrations. Figure 25 compares the predicted bromine speciation for the low quench condition to the high quench condition. The high quench condition is predicted to produce more $\mathrm{Br}_{2}$ than the low quench condition and this is consistent with the 2010 Bozzelli mechanism and the comparison in Figure 24 that shows higher levels of oxidation at the high quench rate. 


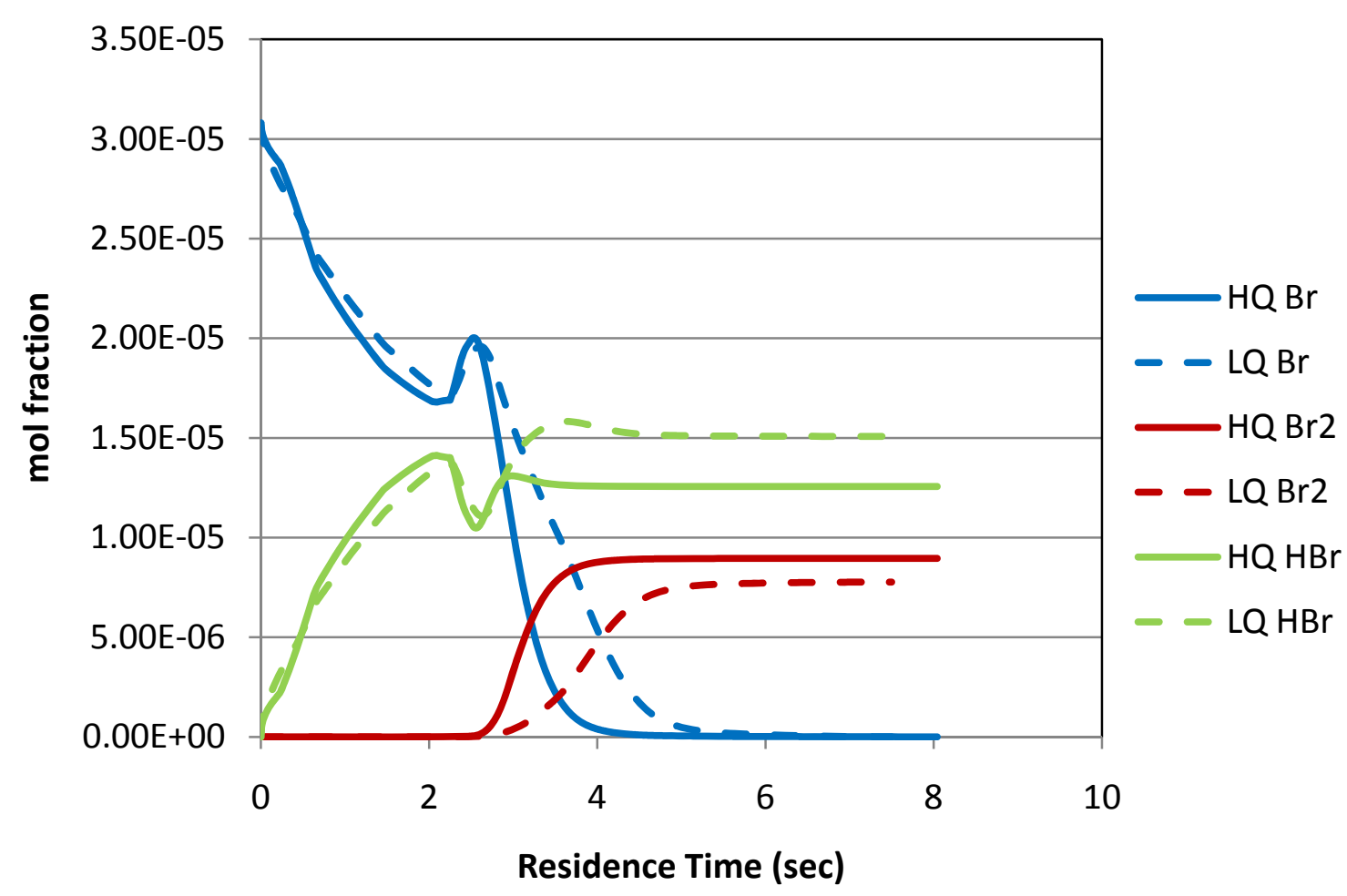

Figure 25. Comparison of predicted bromine species using the high or low quench rate and $30 \mathrm{ppm} \mathrm{Br}$.

\section{Implications for Full-Scale Systems}

The modified Bozzelli $2010 \mathrm{Hg}-\mathrm{Cl}$ and Bozzelli $2010 \mathrm{Hg}$-Br mechanisms were incorporated into the full REI mechanism (with submechanisms for halogens, $\mathrm{NO}_{\mathrm{x}}, \mathrm{SO}_{\mathrm{x}}$, and hydrocarbons). This full mechanism was then incorporated into REI’s MerSim model. MerSim is a full power plant model used to track mercury emissions. To assess the implications of the new mercury-halogen, homogeneous kinetics, several cases were run without heterogeneous reactions and compared to measured, full-scale mercury conentrations.

Figure 26 shows the comparison between mercury measurements and modeling at a plant burning a high chlorine (1440 ppm, dry) bituminous coal. Figure 27 shows the comparison between mercury measurements and modeling at a plant with bromine injection (158 ppm on coal, dry). Without heterogeneous reactions (homogenous reactions only, using the new $\mathrm{Hg}-\mathrm{Cl}$ and $\mathrm{Hg}$-Br kinetic sets), the modeling results do not agree with the measurements. While the model predicts some oxidation, gas-phase kinetics alone under- predict the extent of oxidation in full-scale systems. Heterogeneous kinetics are necessary to accurately model mercury oxidation by bromine at full scale. 


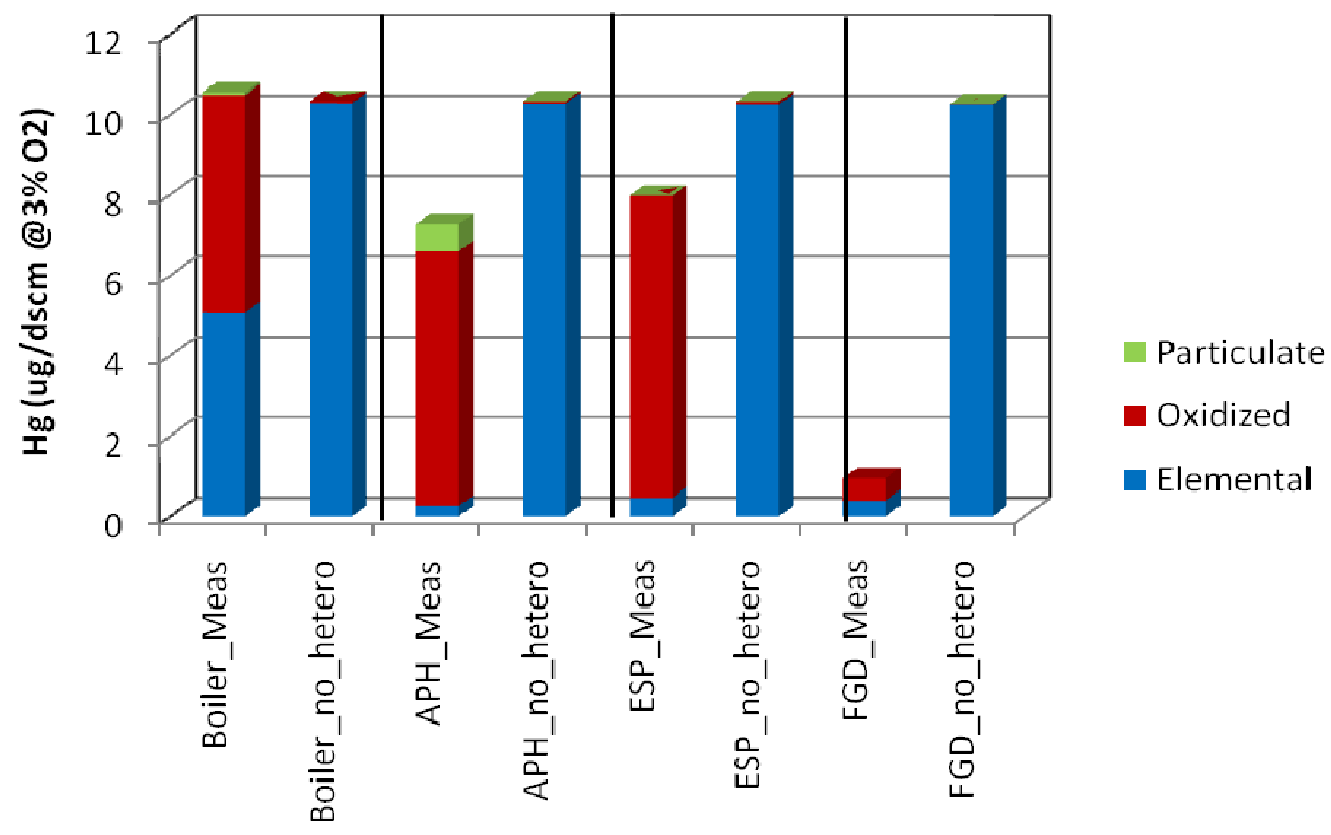

Figure 26. Comparison of measured mercury levels and model results using the new Hg$\mathrm{Cl}$ and $\mathrm{Hg}-\mathrm{Br}$ kinetic sets without heterogeneous reaction at a power plant burning high chlorine bituminous coal.

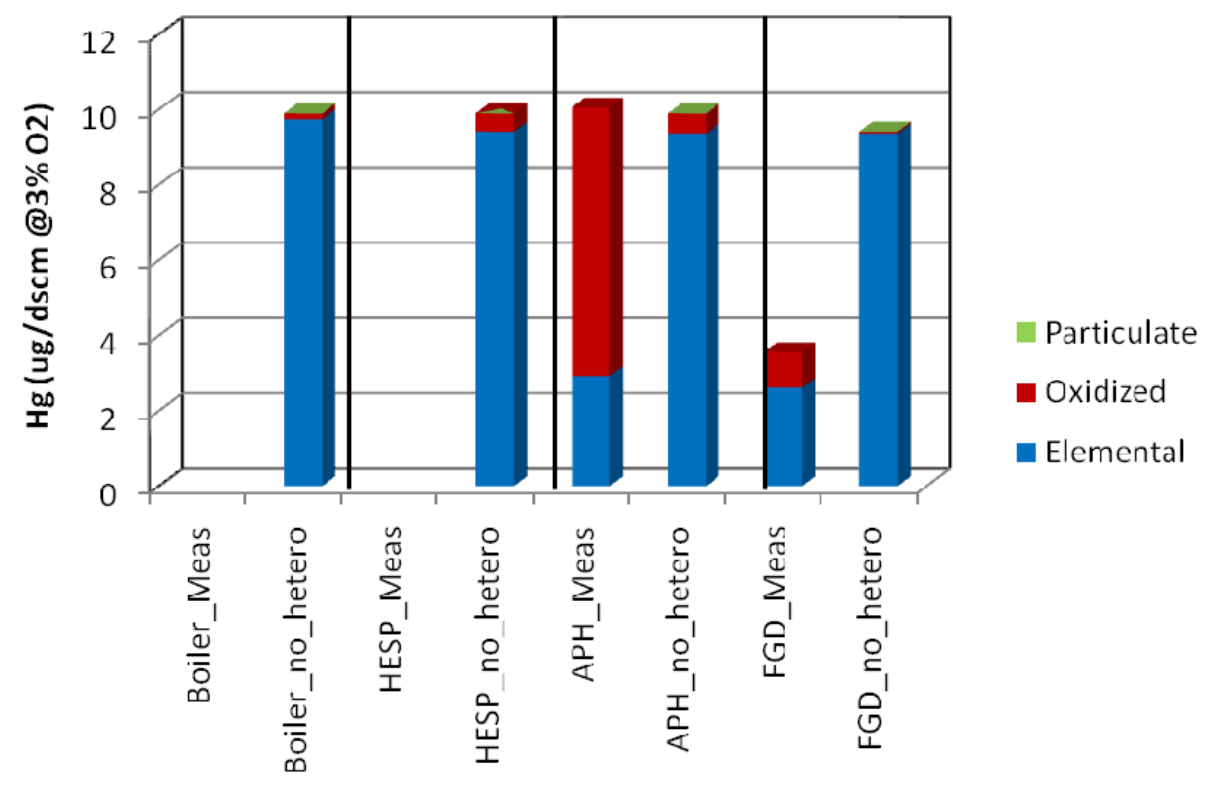

Figure 27. Comparison of measured mercury levels and model results using the new Hg$\mathrm{Cl}$ and $\mathrm{Hg}$-Br kinetic sets without heterogeneous reaction at a power plant with bromine injection. 


\section{CONCLUSIONS}

In the wet conditioning system used to speciate mercury in the laboratory experiments, a negative bias on total mercury was observed. That is, the stannous chloride solution used in the conditioning system to convert all mercury to total mercury did not provide complete conversion of oxidized mercury to elemental when bromine was added to the combustion system, resulting in a low bias for the total mercury measurement. The extent of the bias was reduced by the use of a hydroxylamine hydrochloride solution instead of the stannous chloride solution. The elemental mercury measurement did not appear biased when bromine was added to the reactor, based on a series of experiments in which substitutions were made in the composition of the impingers in the sample conditioning system.

Bromine was shown to be much more effective for post-flame, homogeneous oxidation of mercury than chlorine. The oxidation of mercury by chlorine was not affected by doubling the quench rate in the furnace, within experimental uncertainty. However, the oxidation of mercury by bromine was sensitive to quench rate: doubling the quench rate (from 210 to $440 \mathrm{~K} / \mathrm{s}$ ) resulted in about a $40 \%$ decrease in mercury oxidation. Mercury oxidation is initiated post-flame by free radicals, the concentrations of which are sensitive to cooling rate in the gas.

The simultaneous presence of bromine and chlorine in the system increased the extent of mercury oxidation that would have been obtained with bromine alone. This increase was fairly minor and was proportional to the chlorine concentration. The increase was higher with the low quench profile.

Addition of NO to the flame (up to $400 \mathrm{ppmv}$ ) had no impact on mercury oxidation by chlorine or bromine. Addition of $\mathrm{SO}_{2}$ had no effect on mercury oxidation by chlorine at $\mathrm{SO}_{2}$ concentrations below about $400 \mathrm{ppmv}$; some increase in mercury oxidation was observed at $\mathrm{SO}_{2}$ concentrations of $400 \mathrm{ppmv}$ and higher. In contrast, the presence of $\mathrm{SO}_{2}$ resulted in a considerable reduction in mercury oxidation by bromine, even at concentrations as low as $50 \mathrm{ppm} \mathrm{SO}_{2}$. Sulfur dioxide concentration measurements made along the reactor and conditioning system as well as the results of injecting $\mathrm{SO}_{2}$ at different points along the system, indicated that the observed inhibitory effect of $\mathrm{SO}_{2}$ on mercury oxidation by bromine could be due to reactions between $\mathrm{SO}_{2}$ and oxidized mercury species in the $\mathrm{KCl}$ solution on the elemental side of the conditioning system. Those interactions were partially eliminated by using a $\mathrm{NaOH}$-containing impinger or fixed-bed reactor upstream of the $\mathrm{KCl}$ impinger.

The data generated in this program are the first homogeneous laboratory-scale data on bromine-induced oxidation of mercury in a combustion system. Five $\mathrm{Hg}-\mathrm{Cl}$ and three $\mathrm{Hg}$ $\mathrm{Br}$ mechanisms, some published and others under development, were evaluated and compared to the new data. The Hg-halogen mechanisms were combined with submechanisms from Reaction Engineering International for $\mathrm{NO}_{\mathrm{x}}, \mathrm{SO}_{\mathrm{x}}$, and hydrocarbons. The homogeneous kinetics under-predicted the levels of mercury oxidation observed in 
full-scale systems. This shortcoming can only be corrected by including heterogeneous kinetics in the model calculations. 


\section{GRAPHICAL MATERIAL LIST}

Figure 1. Sketch of the homogeneous mercury reactor ${ }^{9}$.

Figure 2. Temperature profiles in the homogeneous mercury reactor.

Figure 3. Mercury analysis system ${ }^{9}$.

Figure 4. Measured total (HgT) and elemental mercury (Hg0) versus time, with and without bromine injection through burner, obtained with the high quench temperature profile. The total mercury concentration should be constant at $25 \mu \mathrm{g} / \mathrm{m}^{3}$.

Figure 5. Losses in total mercury when using different concentrations of the $\mathrm{SnCl}_{2}-\mathrm{HCl}$ solution on the total mercury side of the sample conditioning system with $50 \mathrm{ppmv}$ bromine (as $\mathrm{HBr}$ equivalent), $30 \mathrm{ppmv} \mathrm{NO}$, and the high quench temperature profile.

Figure 6. Losses in total mercury when using additional $\mathrm{NaOH}$ impingers on the total mercury side of the sample conditioning systems with 50 ppmv bromine (as $\mathrm{HBr}$ equivalent), $30 \mathrm{ppmv} \mathrm{NO}$, and the high quench temperature profile.

Figure 7. Losses in total mercury using a solution of $\mathrm{NH}_{2} \mathrm{OH}^{*} \mathrm{HCl}-\mathrm{NaOH}$ instead of $\mathrm{SnCl}_{2}-\mathrm{HCl}$ on the total mercury side of the sample conditioning system with $50 \mathrm{ppmv}$ bromine (as $\mathrm{HBr}$ equivalent), $30 \mathrm{ppmv} \mathrm{NO}$, and the high quench temperature profile.

Figure 8. Decrease in elemental mercury using different impinger solutions on the elemental mercury side of the sample conditioning system with $50 \mathrm{ppmv}$ bromine (as $\mathrm{HBr}$ equivalent), $30 \mathrm{ppmv} \mathrm{NO}$, and the high quench temperature profile.

Figure 9. Effect of $\mathrm{SO}_{2}$ on mercury oxidation by bromine with and without an additional $\mathrm{NaOH}$ impinger before the $\mathrm{KCl}$ impinger on the elemental side of the conditioning system at 50 ppmv bromine (as $\mathrm{HBr}$ equivalent), 30 ppmv NO, and with the high quench temperature profile.

Figure 10. Effect of $\mathrm{SO}_{2}$ on mercury oxidation by bromine using a packed bed of $\mathrm{NaOH}$ pellets at $120^{\circ} \mathrm{C}$ before the $\mathrm{KCl}$ impinger on the elemental side of the conditioning system. The reactor conditions were 50 ppmv bromine (as $\mathrm{HBr}$ equivalent), $30 \mathrm{ppmv} \mathrm{NO}$, and high quench temperature profile.

Figure 11. Homogeneous mercury oxidation with addition of chlorine or bromine, 30 ppmv NO at high and low quench rates.

Figure 12. Homogeneous mercury oxidation at various concentrations of chlorine and bromine and 30 ppmv NO. The high quench temperature profile was used.

Figure 13. Oxidation of mercury by chlorine as a function of quench rate with $30 \mathrm{ppmv}$ NO. 
Figure 14. Oxidation of mercury by bromine as a function of quench rate with $30 \mathrm{ppmv}$ NO.

Figure 15. Oxidation of mercury by bromine and chlorine as a function of quench rate and chlorine concentration with 30 ppmv NO and a constant bromine concentration of 25 ppm (as $\mathrm{HBr}$ equivalent).

Figure 16. Effect of $\mathrm{SO}_{2}$ and $\mathrm{NO}$ on mercury oxidation by chlorine: (a) low quench rate; (b) high quench rate.

Figure 17. Effect of NO on mercury oxidation by bromine at high quench rate.

Figure 18. Effect of $\mathrm{SO}_{2}$ on mercury oxidation by $45 \mathrm{ppm}$ bromine (as $\mathrm{HBr}$ equivalent) using the high quench temperature profile. In one case the $\mathrm{SO}_{2}$ was added through the burner, in the other it was added directly to the $\mathrm{KCl}$ impinger.

Figure 19. Sample points for $\mathrm{SO}_{2}$ measurements.

Figure 20. $\mathrm{SO}_{2}$ concentration measurements with and without $50 \mathrm{ppm}$ bromine (as $\mathrm{HBr}$ equivalent) using the high quench temperature profile.

Figure 21. Comparison of various Hg-Cl kinetic mechanisms and experimental data.

Figure 22. Zoomed in view of the comparison of various $\mathrm{Hg}-\mathrm{Cl}$ kinetic mechanisms and experimental data.

Figure 23. Results from modifications to Bozzelli $2010 \mathrm{Hg}-\mathrm{Cl}$ mechanism.

Figure 24. Comparison of various Hg-Br kinetic mechanisms and experimental data.

Figure 25. Comparison of predicted bromine species using the high or low quench rate and $30 \mathrm{ppm} \mathrm{Br}$.

Figure 26. Comparison of measured mercury levels and model results using the new Hg$\mathrm{Cl}$ and $\mathrm{Hg}-\mathrm{Br}$ kinetic sets without heterogeneous reaction at a power plant burning high chlorine bituminous coal.

Figure 27. Comparison of measured mercury levels and model results using the new Hg$\mathrm{Cl}$ and $\mathrm{Hg}-\mathrm{Br}$ kinetic sets without heterogeneous reaction at a power plant with bromine injection. 


\section{REFERENCES}

1 Sliger, R.N., Kramlich, J.C., Marinov, N.M. “Development of an Elementary Homogeneous Mercury Oxidation Mechanism.” Presented at the 93rd Annual Meeting of Air \& Waste Management Association, Salt Lake City, UT, June 18-22, 2000.

2 Qiu, J., Sterling, R.O., Helble, J.J. "Development of an Improved Model for Determining the Effects of $\mathrm{SO}_{2}$ on Homogeneous Mercury Oxidation." Presented at the 28th International Technical Conference on Coal Utilization \& Fuel Systems, Clearwater, FL, March 10-13, 2003.

3 Fry, A., Cauch, B., Lighty, J. S., Silcox, G. D., Senior, C. L. "Experimental Evaluation of the Effects of Quench Rate and Quartz Surface Area on Homogeneous Mercury Oxidation," Thirty-First Symposium (International) on Combustion. The Combustion Institute: Pittsburgh, PA, 2006.

4 Smith, C.; Krishnakumar, B.; Helble, J.J. "Homogeneous and Heterogeneous Mercury Oxidation in a Bench-scale Flame-based Flow Reactor." Presented at the Air \& Waste Management 102nd Annual Meeting and Exhibition, Detroit, MI, June 1619, 2009.

5 Afonso, R.F. and C.L. Senior, "Assessment of Mercury Emissions from Full Scale Power Plants.” Presented at the EPRI-EPA-DOE-AWMA Mega Symposium and Mercury Conference, Chicago, IL, August 21-23, 2001.

6 Ghorishi, S.B., Keeney, R.M., Serre, S.D., Jozewich, W.S. Environ. Sci. Technol. 2002, 36, 4454

7 Ehrhardt, K.R., Rohde, A., Bockorn, H., Bozzelli, J.W. "Prediction of the $\mathrm{Cl}_{2}$ and $\mathrm{Br}_{2}$ content in flue gases and selection reduction of $\mathrm{Cl}_{2}$ and $\mathrm{Br}_{2}$ by $\mathrm{H}_{2}$ injection for fuellean conditions." Proceedings of the $6^{\text {th }}$ European Conference on Industrial Furnaces and Boilers, Estoril-Lisboa, Portugal, April 2-5, 2002.

8 Vosteen, B.W., Kanefke, R., Köser, H. VGB PowerTech 2006, 86, 70-75.

9 Fry, A.; Cauch, B.; Lighty, J. S.; Silcox, G. D.; Senior, C. L. Experimental Evaluation of the Effects of Quench Rate and Quartz Surface Area on Homogeneous Mercury Oxidation. Thirty-First Symposium (International) on Combustion. The Combustion Institute: Pittsburgh, PA, 2006.

10 Benson, S.A.; Holmes, M.J.; McCollor, D.P.; Mackenzie, J.M.; Crocker, C.R.; Kong, L.; Galbreath, K.; Dombrowski, K.; Richardson, C. Large-Scale Mercury Control Testing for Lignite-Fired Utilities-Oxidation Systems for Wet FGD. Final Report, 
DOE NETL DE-FC26-03NT41991, Energy \& Environmental Research Center: Grand Forks, ND, March, 2007.

11 Cauch, B.; Silcox, G.; Lighty, J.; Wendt, J.; Fry, A.; Senior, C. Confounding Effects of Aqueous-Phase Impinger Chemistry on Apparent Oxidation of Mercury in Flue Gases. Environ. Sci. Technol. 2008, 42(7), 2594-2599.

12 Bailey, B.W., Lo, F.C. Automated Method for Determination of Mercury. Anal. Chem. 1971 , 43 (11) , 1525-1526.

13 Rio-Segade, S.,Bendicho, C. Determination of total and inorganic mercury in biological and environmental samples with on-line oxidation coupled to flow injection-cold vapor atomic absorption spectrometry. Spectrochimica Acta Part B 1999, 54, 1129-1139.

14 F, Peter., Strunc, G. Semiautomated Analysis for Mercury in whole Blood, Urine and Hair by On-Stream Generation of Cold Vapor. Clin. Chem. 198430 (6), 893.895.

15 Richardson, C. F., Dombrowski, K., Chang, R. "Mercury Control Evaluation of Halogen Injection into Coal-Fired Furnaces.” Presented at Electric Utilities Environmental Conference, Tucson, AZ, January 23-25, 2006.

16 Cao, Y.; Wang, Q.; Chen, C.; Chen, B.;Cohron, M.; Tseng, Y.; Chiu, C.; Chu, P.; Pan, W. Investigation of Mercury Transformation by $\mathrm{HBr}$ Addition in a Slipstream Facility with Real Flue Gas Atmospheres of Bituminous Coal and Powder River Basin Coal. Energy \& Fuels 2007, 21, 2719-2730.

17 Cao, Y.;Gao, Z.; Zhu, J.; Wang, Q.; Huang, Y.;Chiu, C.; Parker, B.; Chu, P.; Pan, W. Impacts of Halogen Additions on Mercury Oxidation, in a Slipstream Selective Catalyst Reduction (SCR), Reactor When Burning Sub-Bituminous Coal. Environ. Sci. Technol. 2008, 42, 256-261.

18 Senior, C.L.; Sarofim, A.F.; Zeng, T.; Helble, J.J.; Mamani-Paco, R., Gas-Phase Transformations of Mercury in Coal-Fired Power Plants. Fuel. Proc. Technol. 2000, 63(2-3), 197-213.

19 Wang, Z.; Pehkonen, S. Oxidation of elemental mercury by aqueous bromine: atmospheric implications. Atmospheric Environment 2004, 38, 3675-3688.

20 Munthe, J.; Xiao, F; Lindqvist, O. The Aqueous Reduction of Divalent Mercury by Sulfite. Water, Air, and Soil Pollution 1991, 56, 621-630.

21 Cohen,M. HYSPLIT Modeling in Phase II of the EMEP Mercury Modeling Intercomparison Study. Presented at the Expert Meeting on Mercury Model Comparison MSC-East, Moscow, Russia. April 15-16, 2003. 
22 Hedgecock, I.M., Trunfio, G.A., Pirrone, N., Sprovieri, F. Mercury chemistry in the MBL: Mediterranean case and sensitivity studies using the AMCOTS (Atmospheric Mercury Chemisty over the Sea) Model. Atmospheric Environment 2005, 39, 72177230.

23 B. Ghorishi, B. Downs, S. Renniger. Role of Sulfides in the Sequestration of Mercury by Wet Scrubbers. Presented to: EPRI-DOE-EPA-AWMA Combined Power Plant Air Pollutant Control Mega Symposium. Baltimore, Maryland. August 28-31, 2006.

24 Pirrone, N.; Mason, R. Mercury Fate and Transport in the Global Atmosphere Emissions, Measurements and Models. Springer Science + Business Media, LLC 2009.

25 Ishikawa et al., Bull. Chem. Soc. Jpn. 1980, 53, 2510-2513.

26 Velzen et al., Int.J.Hydr.Energy 1980, 5, 85-96.

27 Liu, S.-H.; Yan, N.-Q.; Liu, Z.-R.; Qu, Z.; Wang, H.P.; Change, S.-G.; Miller, C. Environ. Sci. Technol. 2007, 41(4), 1405-1412.

28 CaO, Y.; Wang, Q.; Chen, C.' Chen, B.; Cohron, M.; Tseng, Y.; Chiu, C.; Chu, P.; Pan, W.-P. Energy Fuels 2007, 21, 2719-2730.

29 Niksa, S.; Helble, J. J.; Fujiwara, N. Kinetic modeling of homogeneous mercury oxidation: the importance of $\mathrm{NO}$ and $\mathrm{H}_{2} \mathrm{O}$ in predicting oxidation in coal-derived systems. Environ. Sci. Technol. 2001, 35 (18), 3701-3706.

30 Niksa, S.; Helble, J. J.; Fujiwara, N. Interpreting laboratory test data on homogeneous mercury oxidation in coal-derived exhausts. In Proceedings of the $94^{\text {th }}$ Annual Air \& Waste Management Association Conference, Orlando, Fl, June 2001.

31 Widmer, N.C.; West, J., Thermochemical Study of Mercury oxidation in Utility Boiler Fuel Gases. 93 ${ }^{\text {rd }}$ Annual Meeting of the Air \& Waste Management Association, Salt Lake City, UT, June, 2000.

32 Qiu, J.; Sterling, R. O.; Helble, J. J. Development of an improved model for determining the effects of $\mathrm{SO}_{2}$ on homogeneous mercury oxidation. In Proceedings of the 28th International Technical Conference on Coal Utilization \& Fuel Systems, Clearwater, FL, March, 2003.

33 Wilcox, J; Marsden, D. C. J.; Blowers, P. Evaluation of basis sets and theoretical methods for estimating rate constants of mercury oxidation reactions involving chlorine. Fuel Processing Technology 2004, 85 (5), 391-400.

34 Wilcox, J.; Robles, J.; Marsden, D. C. J.; Blowers, P. Theoretically predicted rate constants for mercury oxidation by hydrogen chloride in coal combustion flue gases. Environ. Sci. Technol. 2003, 37 (18), 4199-4204. 
35 Xu, M.; Qiao, Y.; Zheng, C.; Li, L.; Liu, J. Modeling of homogeneous mercury speciation using detailed chemical kinetics. Combustion and Flame 2003, 132, 208218.

36 Niksa, S.; Padak, B.; Krishnakumar, B.; Naik, C.V., Process Chemistry of Br Addition to utility Flue Gas for Hg Emissions Control. Energy and Fuels 2010, 24 (2), 1020-1029.

37 Roesler, J. F.; Yetter, R. A.; Dryer, F. L., Kinetic interactions of CO, $\mathrm{NO}_{\mathrm{x}}$, and $\mathrm{HCl}$ emissions in postcombustion gases. Combustion and Flame 1995, 100, 495-504.

38 N.I.S.T., http://kinetics.nist.gov/kinetics/index.jsp 2006. 


\section{LIST OF ACRONYMS AND ABBREVIATIONS}

OD: $\quad$ Outer diameter

ID: $\quad$ Inner Diameter

SLPM: $\quad$ Standard Liters per Minute

THAM: $\quad$ Tris (Hydroxymethyl) Aminomethane

EDTA: $\quad$ Ethylenediamine tetra acetic acid

HQ: $\quad$ High quench temperature profile (440 K/s)

LQ: $\quad$ Low quench temperature profile $(210 \mathrm{~K} / \mathrm{s})$ 